\title{
Unemployment and econometric learning
}

Article

Accepted Version

Creative Commons: Attribution-Noncommercial-No Derivative Works 4.0

Schaefer, D. and Singleton, C. (2018) Unemployment and econometric learning. Research in Economics, 72 (2). pp. 277296. ISSN 1090-9443 doi: https://doi.org/10.1016/j.rie.2017.10.005 Available at https://centaur.reading.ac.uk/77908/

It is advisable to refer to the publisher's version if you intend to cite from the work. See Guidance on citing.

Published version at: http://dx.doi.org/10.1016/j.rie.2017.10.005

To link to this article DOI: http://dx.doi.org/10.1016/j.rie.2017.10.005

Publisher: Elsevier

All outputs in CentAUR are protected by Intellectual Property Rights law, including copyright law. Copyright and IPR is retained by the creators or other copyright holders. Terms and conditions for use of this material are defined in the End User Agreement.

\section{www.reading.ac.uk/centaur}

\section{CentAUR}

Central Archive at the University of Reading

Reading's research outputs online 


\title{
Unemployment and econometric learning ${ }^{\text {厺 }}$
}

\author{
Daniel Schaefer ${ }^{\mathrm{a}}$, Carl Singleton ${ }^{\mathrm{a}, 1, *}$ \\ ${ }^{a}$ School of Economics, The Univeristiy of Edinburgh, 31 Buccleuch Place, EH8 9JT, UK
}

\begin{abstract}
We apply well-known results of the econometric learning literature to the MortensenPissarides real business cycle model. Agents can always learn the unique rational expectations equilibrium (REE), for all possible well-defined sets of parameter values, by using the minimum-state-variable solution to the model and decreasing gain learning. From this perspective the assumption of rational expectations in the model could be seen as reasonable. But using a parametrisation with UK data, simulations show that the speed of convergence to the REE is slow. This type of learning dampens the cyclical response of unemployment to small structural shocks.
\end{abstract}

Keywords: real business cycle; unemployment; adaptive learning; expectational stability

JEL codes: E24; E32; J64

\section{Introduction}

The Mortensen and Pissarides (1994) model of search and matching frictions has become the foundation for studying the cyclical behaviour of labour markets (see Rogerson and Shimer, 2011 for a survey). The existence of search frictions in labour markets is usually motivated by decentralisation, due to geography and other differences between firms, and because each worker has characteristics which make them more or less suitable for the available jobs. While they search and decide whether or not to accept a match at some agreed upon wage, unemployed workers and firms must form expectations of future variables relevant to their choices, including aggregate conditions. The

\footnotetext{
${ }^{\sqrt{3}}$ We would like to thank participants at the 2014 SGPE Residential Methodology conference, in addition to Jan Grobovšek, Philipp Kircher and Andy Snell for their comments and advice.

${ }^{*}$ Corresponding author: E-mail: carl.singleton@ed.ac.uk

${ }^{1}$ This work was supported by the Economic and Social Research Council (UK) [ES/J500136/1]. Preprint submitted to Elsevier 
decentralised nature of labour markets makes it a priori not obvious that workers and firms are able to correctly forecast these variables at all times. Nonetheless the rational expectations (RE) assumption is usually made in search and matching models. This is likely to pose overly strong requirements on the cognitive abilities of economic agents, and is unrealistic in the presence of potentially frequent structural or policy shocks. Even small departures from RE might alter the qualitative or quantitative predictions of these models.

Here we analyse the equilibrium properties and dynamics of the textbook real business cycle (RBC) Mortensen-Pissarides model (see Hagedorn and Manovskii, 2008 for the standard discrete-time treatment), while representing agents as 'good econometricians,' who form forecasts according to their estimates of some structural model parameters (Evans and Honkapohja, 2001). ${ }^{2}$ We assume that agents employ a recursive least squares (RLS) algorithm to update their parameter estimates when new data becomes available. Econometric (or adaptive) learning can provide a behavioural foundation for $\mathrm{RE}$ if the rational expectations equilibrium (REE) is shown to be learnable or E-stable (Evans and Honkapohja, 2001); i.e. small deviations from this equilibrium are reversed over time, with asymptotic convergence. We show that the model's unique REE is Estable. No parameter restrictions are required to ensure this is the case, beyond those which make the model well-formulated, when agents use a minimum-state-variable rule to form and update their forecasts of so-called labour market tightness. Furthermore, we confirm that this equilibrium is globally stable and satisfies the properties of Strong Estability (i.e. being robust to over-parametrisation of the econometric relationship by the agents). And so from this perspective, the assumption of RE when studying or applying this model would seem to be reasonable.

This article contributes to a significant literature on the more realistic representation of agents as behaving like econometricians in macroeconomic models. Mankiw et al. (2004) offer empirical evidence against RE. Their analysis of surveys of professional forecasters and households finds significant autocorrelation in forecast errors, which is compatible with econometric learning, but not with RE. Milani $(2007,2011)$ also argues for the presence of adaptive learning in the New Keynesian model. He shows that

\footnotetext{
${ }^{2}$ Strictly, the characterisation of agents who behave in this way as 'good econometricians' is used by Branch and McGough (2016). One should think of these as being agents who make conditional forecasts, which are pertinent to their decisions and based on a simple model such as linear regression, and who update this model based on forecast errors.
} 
learning by agents is capable of replacing the other 'mechanical' sources of persistence in these models, such as habits, whilst at the same time increasing the fit to the data as compared to assuming RE. Pfajfar and Santoro (2010) examine a survey of households' inflation forecasts over several decades and conclude that the hypothesis of RE can be rejected, and that there is evidence in support of adaptive learning dynamics. This view is further supported by Berardi and Galimberti (2012), who examine post-WWII US inflation and output growth. Comparing the performance of different adaptive learning algorithms in matching survey forecasts, their results suggest that economic agents form these according to RLS.

The formulation of learning we use here is such that agents need only make onestep-ahead forecasts of the labour market's condition. Ours is not the only recent study to apply the principles of econometric learning to this class of model. From a similar setup, Di Pace et al. (2016) consider an approach where agents must make infinite horizon forecasts about the future paths of wages, unemployment and profits in order to make choices today. This latter type of learning fits into the anticipated utility approach (Kreps, 1998), and has notably been applied to the RBC model by Eusepi and Preston (2011). Di Pace et al. focus on results with constant gain learning, for which there are no equivalent analytical results to the E-stability conditions we consider. The authors use the model to address the 'unemployment volatility puzzle': the inability of the MortensenPissarides model to generate a realistically large amplification of unemployment for a given change in wages or productivity (Shimer, 2005). Under infinite horizon learning, they not only match US professional forecast errors, but also find a greater cyclical unemployment rate response relative to the baseline model. This is driven by persistence or inertia in agents' expectations of the future path of wages, which implies that firms are over-optimistic about future profits, post more vacancies, and thus unemployment is more volatile relative to the REE baseline case. They also find some, but significantly less, propagation of the unemployment response when the model is reformulated in a one-step-ahead forecast guise. Kurozumi and Van Zandweghe (2012) also apply econometric learning to an extended model of the business cycle, which includes sticky prices and monetary policy, as well as labour market search frictions. They analyse determinacy and E-stability conditions, finding that these depend on model parameters. However, both this set-up and that of Di Pace et al. (2016) differ form our own in so far as they move beyond the textbook Mortensen-Pissarides model, and in both cases the agents must forecast several aggregate variables, which do not appear in the reduced form of 
the REE characterisation.

We also present illustrative simulations and analyse the dynamics of the unemployment model, and show that the REE could be a poor approximation to an economy in which agents are econometricians. Convergence to the REE is very slow, even when agents have a short memory or give greater weight to more recent data. If agents must learn the REE, then aggregate variables may be persistently some distance away from their REE equivalents. We also demonstrate how structural shocks generate a more gradual cyclical adjustment of wages after the introduction of learning, and thus predicted unemployment volatility when such shocks occur frequently would be reduced relative to the REE. Therefore we find some different results to Di Pace et al. (2016). The same amplification mechanism described therein is not present here. By keeping closer to the spirit of the most standard RBC variant of the model, in which the only relevant choice is the number of vacancies that firms post, ${ }^{3}$ agents need only estimate a relationship between labour market tightness and productivity to form expectations and close the model, and so wage determination is absorbed. Econometric learning in our set-up then generates inertia in expectations of tightness (and wages) following shocks. ${ }^{4}$

The REE of the model describes a choice of labour market tightness which is independent of the state of unemployment. Therefore, agents' learning of the minimumstate-variable solution implicitly assumes their complete understanding of the economy's dynamics of unemployment and vacancy creation. We consider an alternative decision rule, which relaxes this latter implied assumption. We consider whether or not agents can learn how many vacancies to create in response to an expanded state of the world, which includes the state of unemployment. In other words we also ask if agents can learn the Beveridge curve. This alternative is not E-stable for the complete range of possible model parameters. And where the economy does converge to the REE, it does so more slowly than under the minimum-state-variable representation. In this respect, the approximation of the REE for this model would be even further weakened.

\footnotetext{
${ }^{3}$ With linear production technology this is also equivalent to the decision of vacancy creation or destruction when firms consist of a single worker. Given worker homogeneity, we will rule out states of the world whereby workers would choose not to work.

${ }^{4}$ Although we do not expand on this point later, it is straightforward to see that the minimum-statevariable solution of the model we apply, which agents learn and use to form expectations, could be rewritten in terms of wages and productivity by substituting for the standard 'wage curve' derived from Nash bargaining, (19).
} 


\section{The search and matching model of unemployment}

We outline a discrete-time search and matching model of the labour market, following Merz (1995) and Andolfatto (1996) by assuming that members of a representative household perfectly insure each other against income fluctuations. We derive a difference equation for so-called labour market tightness which summarises its equilibrium, thus analogous to the treatment in Hagedorn and Manovskii (2008). ${ }^{5}$ This can be regarded as a textbook model, which has been applied, critiqued and extended exhaustively in the literature, not least in attempts to solve the unemployment volatility puzzle.

\subsection{The labour market}

There is a continuum of identical, risk-neutral workers with total measure one, and an infinite horizon. The matching function $M\left(u_{t}, v_{t}\right)$ provides the number of successful matches in period $t$. It is increasing and concave in both of its arguments, $u_{t}$ and $v_{t}$, which represent the share of the total workforce currently unemployed and the level of vacancies relative to the size of the workforce respectively. Matches and separations occur after agents in the economy have made decisions, i.e. at the end of each period. A Cobb-Douglas, constant returns to scale matching function is chosen, due to its simplicity, well-known features and being most common in the literature:

$$
M\left(u_{t}, v_{t}\right)=\mu u_{t}^{\alpha} v_{t}^{1-\alpha}, \quad \mu>0, \quad \alpha \in(0,1)
$$

where $\mu$ gives a measure of matching efficiency and $\alpha$ the elasticity of the number of matches with respect to unemployment. We define the level of labour market tightness as

$$
\theta_{t}=\frac{v_{t}}{u_{t}}
$$

Unemployed workers and vacancies are matched randomly, and so the probability of a firm filling an open vacancy each period is

$$
q\left(\theta_{t}\right)=\frac{M\left(u_{t}, v_{t}\right)}{v_{t}}=\mu \theta_{t}^{-\alpha} .
$$

\footnotetext{
${ }^{5}$ Our set-up of the model only differs in so far as we describe a representative household and firm, rather than a continuum of the latter. The characterisation of the equilibrium is approximately identical, though we hope our exposition is more familiar as an extended RBC model with aggregate uncertainty.
} 
The corresponding probability that an unemployed worker gets matched to an open vacancy is

$$
\theta_{t} q\left(\theta_{t}\right)=\frac{M\left(u_{t}, v_{t}\right)}{u_{t}}=\mu \theta_{t}^{1-\alpha} .
$$

Matches are destroyed with probability $\lambda \in[0,1]$. Unemployment changes between periods due to inflows, caused by exogenous separations, and outflows from new matches. The resulting law of motion for the share of workers unemployed at the beginning of period $t+1$ is

$$
u_{t+1}=u_{t}+\left(1-u_{t}\right) \lambda-\theta_{t} q\left(\theta_{t}\right) u_{t}
$$

whereby the final two terms measure these inflows and outflows respectively. The steady-state level of unemployment, where these flows are equal, for given $\theta_{t}$ is

$$
u_{t}^{*}=\frac{\lambda}{\lambda+\theta_{t} q\left(\theta_{t}\right)} .
$$

\subsection{The household}

For expositional simplicity we consider an economy comprising a single infinitelylived representative household of size one, in which all workers are identical and risk neutral. There is perfect consumption insurance across its members. In period $t, n_{t}$ of the household's members are employed and $\left(1-n_{t}\right)$ are waiting for a match. In other words, labour supply is inelastic, which can be ensured by assuming that the equilibrium wage is always strictly greater than the per-period utility value from non-employment $b$; formally we assume $w_{t}>b \geq 0$. The household discounts each additional period's utility by a factor $\delta \in(0,1)$. In period $t$ the household has risk-neutral preferences over income $a_{t}$ and has expected lifetime utility

$$
E_{t}^{*}\left[\sum_{s=0}^{\infty} \delta^{t+s} a_{t+s}\right],
$$

where $E_{t}^{*}$ denotes expectations (not necessarily rational). Income is given by

$$
a_{t}=w_{t} n_{t}+b\left(1-n_{t}\right)+D_{t},
$$

with $w_{t} n_{t}$ and $b\left(1-n_{t}\right)$ denoting total income from labour and non-employment respectively, and $D_{t}$ are dividends from a representative firm, which is owned by the household. 
This household can also be represented by the Bellman equation

$$
W\left(n_{t}\right)=w_{t} n_{t}+D_{t}+b\left(1-n_{t}\right)+\delta E_{t}^{*}\left[W\left(n_{t+1}\right)\right],
$$

where $W\left(n_{t}\right)$ represents the household's current value function, with their state of the world given by the employment level $n_{t}=1-u_{t}$. The household takes as given wages $w_{t}$, dividends from the representative firm $D_{t}$ and labour market tightness $\theta_{t}$. The household's expected continuation value is $E_{t}^{*}\left[W\left(n_{t+1}\right)\right]$. The law of motion for employment follows directly from (5), and is given by

$$
n_{t+1}=(1-\lambda) n_{t}+\theta_{t} q\left(\theta_{t}\right)\left(1-n_{t}\right)
$$

Applying the envelope theorem to (9) and using the law of motion (10), the marginal value of household employment is given by

$$
\frac{\partial W\left(n_{t}\right)}{\partial n_{t}}=w_{t}-b+\delta\left(1-\lambda-\theta_{t} q\left(\theta_{t}\right)\right) \frac{\partial E_{t}^{*}\left[W\left(n_{t+1}\right)\right]}{\partial n_{t+1}},
$$

i.e. the net utility value from wages exceeding non-employment income plus the discounted expected continuation value from additional employment.

\subsection{The firm}

The production side of the economy consists of a representative firm. This firm employs workers and produces output $y_{t} n_{t}$, where $y_{t}$ is the marginal product of labour. We assume that the process of worker productivity is a stationary AR(1) process in logs:

$$
\log \left(y_{t}\right)=\rho \log \left(y_{t-1}\right)+\varepsilon_{t}, \quad \rho \in[0,1),
$$

with some initial condition $y_{0}$ and $\varepsilon_{t}$ being drawn as an iid zero-mean shock. Because labour is the only input into production, the firm maximises profits by choosing the level of employment, subject to the law of motion for the labour market. However, due to the exogeneity of separations, the optimal choice for the level of employment and the optimal quantity of vacancies to open coincide. For each vacancy held open the firm has to pay per-period unit cost $c>0$. The objective of the firm is to maximise the expected value of current and future profits, given by

$$
E_{t}^{*}\left[\sum_{s=0}^{\infty} \delta^{t+s}\left(y_{t+s} n_{t+s}-w_{t+s} n_{t+s}-c v_{t+s}\right)\right] .
$$


Because the firm is owned by the household, the firm discounts future profits using the same discount factor as the household. The firm takes wages $w_{t}$ and labour market tightness $\theta_{t}$ as given. Employment at the firm follows the law of motion

$$
n_{t+1}=(1-\lambda) n_{t}+q\left(\theta_{t}\right) v_{t}
$$

which shows that the more vacancies the firm creates, the higher aggregate employment will be in the next period. Maximising (13), subject to (14), can be represented as the Bellman equation

$$
\Pi\left(v_{t} ; n_{t}, y_{t}\right)=\max _{v_{t} \geq 0}\left(y_{t} n_{t}-w_{t} n_{t}-c v_{t}\right)+\delta E_{t}^{*}\left[\Pi\left(v_{t+1} ; n_{t+1}, y_{t+1}\right)\right],
$$

where $\Pi\left(v_{t} ; n_{t}, y_{t}\right)$ represents the firm's current value function. Profit maximisation in this case implies that the representative firm will open or close vacancies until the marginal cost and benefit of doing so are equal:

$$
\frac{\partial E_{t}^{*}\left[\Pi\left(v_{t+1} ; n_{t+1}, y_{t+1}\right)\right]}{\partial n_{t+1}}=\frac{c}{\delta q\left(\theta_{t}\right)} .
$$

Applying the envelope theorem and using the above first order condition gives the surplus to the firm from employing an additional worker,

$$
\frac{\partial \Pi\left(v_{t} ; n_{t}, y_{t}\right)}{\partial n_{t}}=y_{t}-w_{t}+\frac{(1-\lambda) c}{q\left(\theta_{t}\right)},
$$

i.e. the net profit from employing an additional worker plus the discounted expected continuation value, taking matching frictions into account. The optimal choices of the firm (16) and (17) imply that labour market tightness evolves according to the non-linear difference equation

$$
\frac{c}{\delta q\left(\theta_{t}\right)}=E_{t}^{*}\left[y_{t+1}-w_{t+1}+\frac{(1-\lambda) c}{q\left(\theta_{t+1}\right)}\right]
$$

In other words, the representative firm must form expectations about the right hand side of (18) to optimally choose the number of vacancies to open in the current period. In particular, the firm forecasts labour productivity $y_{t+1}$, the real wage which will be realised next period $w_{t+1}$, and the value of labour market tightness in the next period $\theta_{t+1}$. Note that this problem does not depend on the type of expectations formation; we have not specified how forecasts of the right hand side of (18) are formed. 


\subsection{Wage determination}

Wages are determined by generalised Nash bargaining between the firm and workers over the additional surpluses (11) and (17), with worker bargaining power $\beta \in[0,1]$ : $^{6}$

$$
w_{t}=\arg \max \left(\frac{\partial W\left(n_{t}\right)}{\partial n_{t}}\right)^{\beta}\left(\frac{\partial \Pi\left(v_{t} ; n_{t}, y_{t}\right)}{\partial n_{t}}\right)^{1-\beta} .
$$

Combining the surplus sharing rules which form the solution of this problem, iterating forwards, and using (11), (16) and (17) gives what is referred to in the textbook model as the 'wage curve':

$$
w_{t}=(1-\beta) b+\beta\left(y_{t}+c \theta_{t}\right) .
$$

To ensure employment is always preferred and a wage successfully negotiated we also restrict $y_{t}>b$. Again, we do not have to specify rational expectations to obtain the wage curve.

\subsection{The rational expectations equilibrium}

Our search and matching framework consists of the goods and the labour market. Since our focus is to study the labour market under econometric learning, we abstract from the goods market. This can be justified by Walras' Law, which states that equilibrium in the labour market implies that the goods market clears. The representative household supplies labour inelastically, and thus the REE of the model can be summarised and determined uniquely by the value of labour market tightness at which point the representative firm is indifferent between opening an additional vacancy or not. In other words, the firm has to form expectations about the future state of labour market tightness as this affects the current discounted value of a match. The non-linear difference equation determining this value of $\theta_{t}$, substituting the outcome of the wage bargaining (19) into (18), is given by

$$
\frac{c}{\delta q\left(\theta_{t}\right)}=E_{t}^{*}\left[(1-\beta)\left(y_{t+1}-b\right)+\frac{(1-\lambda) c}{q\left(\theta_{t+1}\right)}-\theta_{t+1} \beta c\right] .
$$

To provide intuition for this expression we stress the similarities to (16). Aggregate labour market tightness $\theta_{t}$ will adjust immediately to deviations from this equality via the

\footnotetext{
${ }^{6}$ Note, it is crucial here that both workers and firms are assumed to form expectations in the same way, using the same rule, as otherwise the Nash bargaining solution would be significantly complicated. In the sense of the model here, since workers own the firm, this is not an unreasonable assumption.
} 
firm instantaneously opening or closing vacancies. Thus today's labour market tightness is determined by expectations of the value of a filled vacancy in the next period. In equilibrium it must also be that $D_{t}=y_{t} n_{t}-w_{t} n_{t}-c v_{t}$.

Given the process for productivity (12), the equilibrium $\theta_{t}$ is the solution of the nonlinear difference equation (20). With this and initial condition $u_{1}$, the remainder of the interesting endogenous variables in the equilibrium, $\left\{a_{t}, w_{t}, v_{t}, u_{t+1}\right\}_{t>0}$, can be obtained using (2), (5), (8) and (19). In the next section we linearise around steady-state values to obtain an analytical solution to (20) and discuss the rational expectations equilibrium.

\section{Linearisation and the rational expectation equilibrium}

To solve the system consisting of (12) and (20), we linearise around deterministic steady-state values $\bar{\theta}$ and $\bar{y}=1:^{7}$

$$
\begin{aligned}
& \theta_{t}=\psi_{0}+\psi_{1} E_{t}^{*} y_{t+1}+\psi_{2} E_{t}^{*} \theta_{t+1}, \\
& y_{t}=(1-\rho)+\rho y_{t-1}+\varepsilon_{t},
\end{aligned}
$$

where the coefficients are functions of the model's parameters and steady state values

$$
\begin{aligned}
& \psi_{0}=\left[1-\psi_{2}\right] \bar{\theta}-\psi_{1} \bar{y} \\
& \psi_{1}=(1-\beta) \delta \bar{\theta} q(\bar{\theta})(c \alpha)^{-1} \\
& \psi_{2}=\delta\left[(1-\lambda)-\beta \bar{\theta} q(\bar{\theta}) \alpha^{-1}\right] .
\end{aligned}
$$

We now assume that expectations are rational, that is, the firm and the household take all available information into account and forecast $\theta$ without systematic errors. We denote the rational expectations operator by $E_{t}$. Linear RE models where agents form expectations regarding an endogenous variable can have multiple equilibria (or bubble solutions, not related to economic fundamentals). ${ }^{8}$ If there are multiple stable REEs then a model is said to be indeterminate. In Appendix A.2 we show that a unique stable equilibrium exists so long as $\left|\psi_{2}\right|<1$. Intuitively, this condition requires that the shocks

\footnotetext{
${ }^{7}$ See Appendix A.1 for derivation and all subsequently defined parameters, such as $\psi$ 's, expressed in terms of the model parameters and steady-state values.

${ }^{8}$ The literature on bubbles and the related concept of indeterminacy is reviewed in Benhabib and Farmer (1999). The classic reference on bubble solutions is Blanchard and Watson (1983); see also Bullard and Mitra (2002) for an analysis of indeterminacy in a New Keynesian framework.
} 
$\varepsilon$ are transitory and $\theta$ returns to its steady state value, analogous to a stationary firstorder autoregressive process. The solution in this case to the system (21) and (22) is obtained by using the method of undetermined coefficients. After substituting $E_{t} y_{t+1}=$ $(1-\rho)+\rho y_{t}$ in $(21)$, the solution can be guessed to have the form

$$
\theta_{t}=A+B y_{t-1}+C \varepsilon_{t}
$$

since the only predetermined variable in the above system is $y_{t-1}$. The parameters $A$, $B$, and $C$ of the reduced form are functions of the parameters in (21) and (22). ${ }^{9}$ Using equation (23), RE about next period's labour market tightness are given by

$$
E_{t} \theta_{t+1}=A+B y_{t}
$$

since $E_{t} \varepsilon_{t+1}=0$. The parameters used thereby to estimate $\theta_{t+1}$ are true values, that is the firm and the household know the true underlying functional forms and their associated parameter values. When $\varepsilon_{t}$ is realised in period $t$, it becomes part of the information set of firms and households and the resulting forecast $E_{t} \theta_{t+1}$ leads to an immediate adjustment of vacancies, such that the difference between $E_{t} \theta_{t+1}$ and $\theta_{t+1}$ is only from the next period's shock $C \varepsilon_{t+1}$. In the absence of new shocks the firm and the household forecast the response of market tightness to productivity correctly using (24).

\section{Adding econometric learning to the model}

We now depart from RE and apply the concept of econometric learning to this model. Unlike the application of Di Pace et al. (2016), who suggest that agents might need to form infinite horizon forecasts of multiple variables, such as wages or firm profits, we depart from the REE summarised above by the single choice variable $\theta_{t}$, which just requires a one-step-ahead forecast of $\theta_{t+1}$. Kurozumi and Van Zandweghe (2012) have also considered the role of learning when agents need to make one-step-ahead forecasts in the presence of labour search frictions. However, their model also includes sticky prices and monetary policy, involves forecasting over several aggregate variables, and the determinacy of the REE is not always certain. In what follows the expectational stability results become more clear-cut.

\footnotetext{
${ }^{9}$ See Appendix A.3 for a description of how (23) can be obtained from (21) and (22), and also A, B and $C$ in terms of the model parameters.
} 


\subsection{E-Stability of the MSV solution}

We relax the assumption of RE by modelling agents as econometricians attempting to estimate the parameters $A, B$, and $C$, which underpin the true motion of the economy under uncertainty. Agents are endowed with a perceived law of motion (PLM) in the economy of the MSV form (23), because we derived its functional form without having to impose rational expectations. ${ }^{10}$ In other words, agents know the structure of the economy as expressed in the system (21) and (22), but the parameter values are unknown to them. They make corresponding estimates of the true coefficients in period $t$, given by $\hat{A}_{t}, \hat{B}_{t}$ and $\hat{C}_{t}$, and update these each period when new data becomes available. Therefore, the household and firm forecast as under RE in (24), but instead of the true parameter values they use estimates $\hat{A}_{t}$ and $\hat{B}_{t}$ to forecast labour market tightness

$$
E_{t}^{*} \theta_{t+1}=\hat{A}_{t}+\hat{B}_{t} y_{t}
$$

The main difference is that forecasts with rational expectations coincide with the true realisation of next period's $\theta$ on average, whereas this is not the case for econometric learners. They possess less information than rational agents, since they do not know the parameters of the model. We assume econometric learners perform the task of estimating parameters using recursive least squares (RLS). This is the most widely used estimation technique in the learning literature and Berardi and Galimberti (2012) provide evidence that this estimator matches surveys of forecasts of US time series closely. ${ }^{11}$ Let the vector of parameter estimates be denoted by $x_{t-1}^{\prime}=\left(\hat{A}_{t}, \hat{B}_{t}\right)$, then the general recursive updating algorithm can be represented by

$$
x_{t}=x_{t-1}+g_{t} Q\left(\theta_{t}-\hat{A}_{t}-\hat{B}_{t} y_{t-1}\right)
$$

which shows that agents update their previous parameter estimates $x_{t-1}$ by a function of the observed forecasting error. The function $Q$ and the so-called "gain parameter" $g_{t}$ are further described below. There are potential problems of simultaneity in forward looking models. Therefore, it is assumed that although agents forecast $\theta_{t+1}$ using $y_{t}$, the variable $y_{t}$ is not in the information set for the estimation of $\hat{A}_{t}$ and $\hat{B}_{t}$. As proved by

\footnotetext{
${ }^{10}$ If agents are not able to learn the simplest representation (as few state variables as possible), they cannot be expected to learn equilibria containing more state variables and to coordinate behaviour towards them.

${ }^{11}$ The presented algorithm is comparable to a restricted form of the Kalman filter. For further discussion see Berardi and Galimberti (2013).
} 
Marcet and Sargent (1989), this does not alter the asymptotic stability results obtained in the following, as compared to an algorithm allowing for simultaneity, so long as agents are assumed to ignore outliers, defined as being observations outside of some predetermined range. This timing assumption is usually thought of as realistic, since robust macroeconomic data is only available to decision makers with a substantial lag. ${ }^{12}$

Since the current value of labour market tightness depends on the prediction of next period's value, agents estimates have the potential to affect the path of labour market tightness. To see this, we substitute the stochastic process of labour productivity and the econometric forecast (25) into (21), which gives the actual law of motion (ALM) for labour market tightness:

$$
\begin{aligned}
\theta_{t}= & \psi_{0}+\psi_{1}(1-\rho)(1+\rho)+\psi_{2} \hat{A}_{t}+\psi_{2} \hat{B}_{t}(1-\rho) \\
& +\left(\psi_{1} \rho+\psi_{2} \hat{B}_{t}\right) \rho y_{t-1} \\
& +\left(\psi_{1} \rho+\psi_{2} \hat{B}_{t}\right) \varepsilon_{t} .
\end{aligned}
$$

This defines the following $T$-mapping from the PLM, $\theta_{t}=A+B y_{t-1}+C \varepsilon_{t}$, to the ALM:

$$
\begin{aligned}
& T\left(\hat{A}_{t}\right)=\psi_{0}+\psi_{1}(1-\rho)(1+\rho)+\psi_{2} \hat{A}_{t}+\psi_{2} \hat{B}_{t}(1-\rho), \\
& T\left(\hat{B}_{t}\right)=\left(\psi_{1} \rho+\psi_{2} \hat{B}_{t}\right) \rho, \\
& T\left(\hat{C}_{t}\right)=\psi_{1} \rho+\psi_{2} \hat{B}_{t},
\end{aligned}
$$

where the function $T: \mathbb{R}^{N} \rightarrow \mathbb{R}^{N}$ maps the estimated coefficients into the actual parameters, which are in turn determined by the estimates. There is a self-referential feature inherent in all learning models which can be seen in equation (27). Although the estimated parameters are non-stationary during their transition to REE values, learners neglect this fact, since a least squares method assumes the 'true' $A, B$ and $C$ to be constants. Intuitively, if the coefficient which determines the responsiveness to expectations is sufficiently small, then this specification error becomes asymptotically negligible and the economy converges to the REE (Evans and Honkapohja, 2001). The $T$-mapping to $\hat{C}_{t}$ is determined by the other coefficients, and the estimate $\hat{C}_{t}$ is independent of $C$ and does not influence stability results. Therefore, in what follows we refer to the mappings $T\left(\hat{A}_{t}, \hat{B}_{t}\right)$ and for $\hat{C}_{t}: V\left(\hat{B}_{t}\right)$.

\footnotetext{
${ }^{12}$ The assumption also plausibly implies that under subjective expectations agents would only ever enter the wage bargaining process with pre-determined valuations. Otherwise, there would be simultaneity between the bargaining result and subsequent expectations formation.
} 


$$
\begin{aligned}
& \text { Let } z_{t-1}^{\prime}=\left(1, y_{t-1}\right), x_{t-1}^{\prime}=\left(\hat{A}_{t}, \hat{B}_{t}\right) \text { and } \\
& \qquad \theta_{t}=z_{t-1}^{\prime} x_{t-1}+\eta_{t} .
\end{aligned}
$$

The estimation error $\eta_{t}$ is perceived by the agents to be independently and identically distributed iid. However, due to the self-referential nature of the model there is an endogeneity bias which agents are unaware of, and thus $\eta_{t}$ is not truly iid. We define $R_{t}=t^{-1} \sum_{i=1}^{t} z_{i-1} z_{i-1}^{\prime}$, which allows us to write the RLS estimator as

$$
\begin{aligned}
R_{t} & =R_{t-1}+t^{-1}\left(z_{t-1} z_{t-1}^{\prime}-R_{t-1}\right), \\
x_{t} & =x_{t-1}+t^{-1} R_{t}^{-1} z_{t-1}\left(\theta_{t}-z_{t-1}^{\prime} x_{t-1}\right),
\end{aligned}
$$

and thus

$$
x_{t}=x_{t-1}+t^{-1} R_{t}^{-1} z_{t-1}\left(z_{t-1}^{\prime}\left[T\left(\hat{A}_{t}, \hat{B}_{t}\right)-x_{t-1}\right]+V\left(\hat{B}_{t}\right) \varepsilon_{t}\right),
$$

with the gain sequence $1 / t$, often referred to as decreasing gain learning. ${ }^{13}$ This gain guarantees that asymptotically new information is disregarded by agents.

The stability of the system in (29) and (31) with decreasing gain is governed by the following ordinary differential equation (ODE), where $\tau$ denotes 'notional' time:

$$
\frac{d}{d \tau}(\hat{A}, \hat{B})=T(\hat{A}, \hat{B})-(\hat{A}, \hat{B})
$$

The REE is E-stable if (32) is asymptotically locally stable under learning (Evans and Honkapohja, 2001). This is the case, if all the eigenvalues of the Jacobian of $T(\hat{A}, \hat{B})-$ $(\hat{A}, \hat{B})$ have negative real parts. Here the necessary condition for E-stability is $\psi_{2} \rho<1$, with sufficient condition

$$
\psi_{2}=\delta\left[1-\left(\lambda+\frac{\beta \bar{\theta} q(\bar{\theta})}{\alpha}\right)\right]<1 .
$$

This holds for all possible well-defined sets of parameter values, and there is also global convergence to the REE (see Appendix A.4): $\delta \in[0,1), \lambda \in[0,1], \beta \in[0,1], \mu>$ $0, \alpha \in(0,1), c>0$, and which all imply $\bar{\theta} \geq 0$. As explained in the previous section, the model is determinate if $\left|\psi_{2}\right|<1$. We can therefore state the following:

Proposition 4.1. If the economy described by the system (21) and (22) exhibits determ-

\footnotetext{
${ }^{13}$ In the case of constant gain learning the weight given each observation is geometrically declining with the time since it was observed, and the gain sequence would be $0<\gamma<1$.
} 
inacy and the PLM is of the MSV form, and if agents learn using least squares updating, then so long as $\psi_{2}<1$ the unique REE is E-stable.

In other words, the textbook linearised model of labour market search and matching frictions, with homogeneous agents and no-on-the-job search (Pissarides, 2000: Chapter 1), has a unique E-stable equilibrium. Sets of parameter values which move $\psi_{2}$ closer to one will imply slower convergence to the REE. It is intuitive and clear from (33) that these will be parameters which lessen the magnitude of the dynamics in the labour market, such as a small separation probability or low worker bargaining power.

\subsection{Strong E-stability of the MSV solution}

One potential criticism of the econometric learning literature is that it is not clear how agents could settle upon a particular law of motion for the economy. Strong Estability of a system is defined if the previous result is robust to over-parametrisation of the PLM (Evans and Honkapohja, 2001). Assume instead that agents are forming their expectations of $\theta_{t+1}$ according to the general ARMA representation (A.4), and are not endowed with a PLM of the MSV form. Moreover, due to econometric considerations they start with an arbitrarily over-parametrised version,

$$
\theta_{t}=a+\sum_{j=1}^{s} b_{j} y_{t-j}+\sum_{j=1}^{r} c_{j} \theta_{t-j}+\sum_{j=1}^{q} d_{j} \varepsilon_{t-j}+\sum_{j=1}^{l} f_{j} \eta_{t-j}+d_{0} \varepsilon_{t}+f_{0} \eta_{t} .
$$

Accordingly, expectations of $\theta_{t+1}$ take the form:

$$
\theta_{t+1}^{e}=a+\sum_{j=1}^{s} b_{j} y_{t+1-j}+\sum_{j=1}^{r} c_{j} \theta_{t+1-j}+\sum_{j=1}^{q} d_{j} \varepsilon_{t+1-j}+\sum_{j=1}^{l} f_{j} \eta_{t+1-j},
$$

which can be substituted into equation (A.3) to obtain the new ALM and a corresponding $T$-mapping in the same way as before (see Appendix A.5). Let $\mathbf{b}^{\prime}=\left(b_{1}, \ldots, b_{s}\right), \mathbf{c}^{\prime}=$ $\left(c_{1}, \ldots, c_{r}\right), \mathbf{d}^{\prime}=\left(d_{0}, \ldots, d_{q}\right)$, and also $\mathbf{f}^{\prime}=\left(f_{0}, \ldots, f_{l}\right)$. Further, define $\phi^{\prime}=\left(a, \mathbf{b}^{\prime}, \mathbf{c}^{\prime}, \mathbf{d}^{\prime}, \mathbf{f}^{\prime}\right)$. According to the E-stability principle, the ODE governing the stability of the above system is given by

$$
\frac{d \phi}{d \tau}=T(\phi)-\phi
$$

To investigate whether agents will detect the over-parametrisation and converge towards the MSV solution, the stability of (36) at the REE must be studied. In Appendix A.5 we show the following: 
Proposition 4.2. If the economy described by the system (21) and (22) exhibits determinacy and the PLM is of the over-parametrised ARMA form, and if agents learn using least squares updating, then so long as $\psi_{2}<1$ the unique REE is Strongly E-stable.

\section{Analysis}

We present a brief analysis of the unemployment model with econometric learning described above. We consider two illustrative simulations to demonstrate the implied speed of convergence and dynamics of the model. First, we demonstrate E-stability when starting 'realistically' far away from the REE. Second, with agents initially assumed to have learned the REE, we consider the impact of a structural shift implied by an arbitrary change in some parameter value. We then discuss the speed of convergence and results with constant gain learning. We also consider the implications if we relax an implicit assumption that agents understand the joint dynamics of unemployment and vacancy creation.

\subsection{Simulations}

We follow an illustrative parametrisation strategy, using seasonally adjusted UK quarterly ${ }^{14}$ data for the period 1998-2013 (see Appendix B for a brief discussion of this strategy). ${ }^{15}$ Table 1 gives the complete list of parameters and implied values of the endogenous variables for the deterministic steady-state equilibrium. Summary statistics of some UK labour market variables are described in Table 2, which are consistent with the parametrisation here.

For completeness we write out in full the stochastic recursive sequence that repres-

\footnotetext{
${ }^{14}$ As pointed out by a referee, the timing structure of the model implies an average time between hiring and production for workers of one and a half months, and when calibrating a model with labour market search frictions it would be more generally preferable to use a monthly periodicity. But when we wish to capture the role of aggregate uncertainty affecting agents' decisions, since UK National Statistics are generally released quarterly, we believe our timing is justified. What matters for plausibly estimating the role of learning dynamics is the frequency at which it is assumed new aggregate data becomes available to the agents, since between times the agents' model parameters will remain unchanged.

${ }^{15}$ All data used and described are from the Office for National Statistics, accessed 01/08/2014. Labour market data are for those aged 16 and over. For a more complete calibration of the unemployment model using UK data see Burgess and Turon (2010).
} 
Table 1: Assumed/estimated parameter values and steady-state equilibrium

\begin{tabular}{c|c}
\hline Parameter & Assumed value \\
\hline$y$ - labour productivity & 1 \\
$b$ - non-employment flow value & 0.8 \\
$c$ - vacancy flow cost & 0.25 \\
$\lambda$ - separation rate & 0.023 \\
$\mu$ - matching efficiency & 0.56 \\
$\alpha$ - matching elasticity & 0.67 \\
$\beta$ - worker bargaining power & 0.67 \\
$\delta$ - discount factor & 0.99 \\
$\rho$ - persistence of y & 0.84 \\
$\sigma$ - std dev. of innovations to $y$ & 0.006 \\
\hline Endogenous variable & Steady-state eq. value \\
\hline $\boldsymbol{\theta}$ - tightness & 0.35 \\
$u$ - unemployment & 0.055 \\
$v$ - vacancy rate & 0.019 \\
$w$ - wage & 0.99 \\
\hline
\end{tabular}

Source: authors' calculations.

ents the adaptive learning model, stating from an initial period $t_{0}$ :

$$
\begin{array}{ll}
(I) & u_{t+2}=\lambda\left(1-u_{t+1}\right)+\left[1-\mu\left(z_{t}^{\prime} T\left(x_{t}\right)+V\left(x_{t}\right) \varepsilon_{t+1}\right)^{1-\alpha}\right] u_{t+1}, \\
(I I) & R_{t+1}=R_{t}+\frac{1}{t+1}\left(z_{t} z_{t}^{\prime}-R_{t}\right), \\
(I I I) & x_{t+1}=x_{t}+\frac{1}{t+1} R_{t+1}^{-1} z_{t}\left\{z_{t}^{\prime}\left[T\left(x_{t}\right)-x_{t}\right]+V\left(x_{t}\right) \varepsilon_{t+1}\right\} \\
(I V) & y_{t+1}=(1-\rho)+\rho y_{t}+\varepsilon_{t+1}, \\
(V) & \varepsilon_{t+2} \sim \text { i.i.d. } N\left(0, \sigma^{2}\right) .
\end{array}
$$

When written out in sequence order, the simultaneity which requires us to exclude $y_{t}$ from the information set used to estimate $x_{t}$ becomes clearer. The adaptive learning process, which takes place at the beginning of each period, can also be described by Figure 1. To initiate the sequence from $t_{0}$ we must choose initial values $u_{1}, x_{0}, z_{0} R_{0}$ and $\varepsilon_{1}$. The asymptotic properties of decreasing or constant gain least squares recursion will hold irrespective of the initial conditions. As suggested by Carceles-Poveda and Giannitsarou (2007), the approach to setting initial values $z_{0}$ and $R_{0}$ should depend on the particular model in question and the empirical purpose of the researchers. One approach could be to use historic or randomly generated data, with $t_{0}$ set sufficiently large such 
Figure 1: Timeline of the labour market \& agents' learning

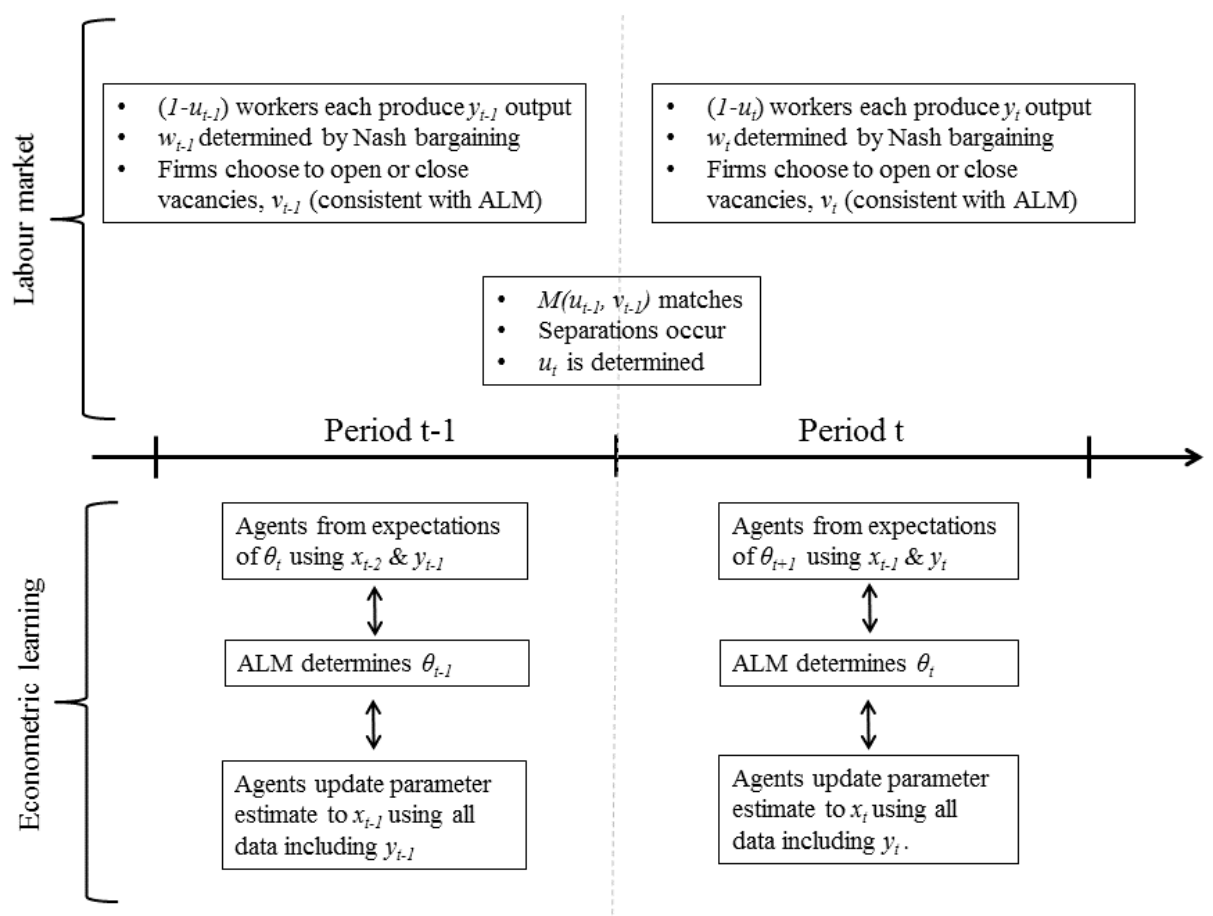

Table 2: Summary statistics of labour market states \& quarterly transition rates: consistent with the model's parametrisation, 2002q1-13q2

\begin{tabular}{c|cc}
\hline & Mean & Std err. \\
\hline Tightness $-\theta_{t}=\frac{v_{t}}{u_{t}}$ & 0.35 & 0.022 \\
Job finding rate $-\theta_{t} q\left(\theta_{t}\right)$ & 0.39 & 0.011 \\
Job separation rate $-\lambda_{t}$ & 0.023 & 0.00093 \\
'Steady-state unemployment rate' $-u_{t}^{*}=\frac{\lambda_{t}}{\lambda_{t}+\theta_{t} q\left(\theta_{t}\right)}$ & 0.56 & 0.0041 \\
Unemployment rate & 0.57 & 0.0022 \\
\hline
\end{tabular}

Source: authors' calculations using UK Labour Force Survey and Labour Market Statistics. The unemployment rate is the share of the economically active population ILO unemployed. The job finding and separation rates are consistent with in reality a three-state system, which includes inactivity; i.e. the job separation rate is not only the direct flow rate from employment to unemployment but in addition the indirect flow via inactivity (see Smith (2011). See Appendix B for more details.

that $R_{0}$ is invertible; in this case $t_{0} \geq 2$. This would be most appropriate when comparing the performance of models which assume that agents are 'good econometricians' against 
real data. However, this gives few clues as to how large $t_{0}$ should be, and the subsequent simulation is likely to be sensitive to this assumed level of agents' memory, particularly for decreasing gain least squares. Another attractive option is to choose initial values from an assumed distribution around the REE.

To set initial conditions here, using the same data used to parametrise the model, we estimate using least squares

$$
\theta_{t}=\kappa_{0}+\text { cubtr }_{t}+B y_{t-1}+\kappa_{1} \zeta_{t-1}+\kappa_{2} \zeta_{t-2}+\zeta_{t}, \quad t=2001 q 3 \ldots 2013 q 3,
$$

where cubtr $_{t}$ represents a cubic time trend to address the possibility that agents could recognise low frequency structural breaks in the relationship, output per worker is normalised but not de-trended, and we include significant MA terms, to account for autocorrelation when the MSV is applied to real world data, which the good econometrician may in practice account for by what we have referred to before as an over-parametrised PLM. ${ }^{16}$ Given an estimate of $\hat{B}$ from (37), we choose an initial value for $\hat{A}$ such that the economy is initially at $\bar{\theta}$, the deterministic steady-state equilibrium. $t_{0}=49$ is the maximum number of UK observations available. Using this approach, we set $R_{0}=\left(\begin{array}{cc}1 & 1 \\ 1 & 1.0014\end{array}\right)$, $x_{0}^{\prime}=(-1.42,1.77), z_{0}^{\prime}=(1,1), \varepsilon_{1}=0$ and

$$
u_{1}=\frac{\lambda}{\lambda+\mu\left(z_{0}^{\prime} T\left(x_{0}\right)\right)^{1-\alpha}} \quad(=0.265) .
$$

To analyse the impact of adaptive learning we focus on the simulated time paths of wages and the tightness parameter, which are independent of the choice of $u_{1}$. With the parametrisation described above, the REE parameters of the MSV solution are given by $x_{R E E}^{\prime}=(-0.70,1.055)$. The elasticity of $\theta$ to productivity at the long-run average level is then around three, which is significantly lower than observed in the data.

Figure 2 demonstrates a simulation over a hundred quarters of wages, unemployment and labour market tightness for the baseline case of agents with RE. ${ }^{17}$ Unsurprisingly, as is common with this class of models, and as described in Table 3 when compared with Table 2, the generated sample path under the REE significantly underestimates

\footnotetext{
${ }^{16}$ In determining initial conditions, one could also consider the class of GARCH, error correction, or even VAR models, however we believe this would be an unnecessarily significant leap from the straightforward least squares updating we assume that a 'good econometrician' carries out in practice, and which constitutes the learning algorithm we study here.

${ }^{17}$ See Appendix Figure $\mathrm{C} 1$ for the simulated paths of output per worker and shocks used in all simulations here. These were generated using the random number seed 42 in the Python Numpy application.
} 
the variance of tightness in the UK labour market; i.e. the model does not generate a realistic magnitude of unemployment fluctuations over the business cycle, with the standard deviation being approximately a quarter of that observed in the data.

Table 3: Simulation results under the REE, decreasing and constant gain learning

\begin{tabular}{c|c|ccc}
\hline Number of qtrs after init. val. & $\begin{array}{c}20 \\
\text { Std dev. }\end{array}$ & Std dev. & Min. & Max. \\
\hline REE & & & & \\
$w$ & 0.011 & 0.0085 & 0.97 & 1.01 \\
$u$ & 0.00054 & 0.00053 & 0.054 & 0.056 \\
$\theta$ & 0.015 & 0.012 & 0.032 & 0.037 \\
\hline Decreasing gain & & & & \\
$w$ & 0.012 & 0.0092 & 0.97 & 1.01 \\
$u$ & 0.00072 & 0.0070 & 0.054 & 0.057 \\
$\theta$ & 0.0020 & 0.0016 & 0.031 & 0.038 \\
\hline Constant gain $(\gamma=0.05)$ & & & & \\
$w$ & 0.012 & 0.090 & 0.97 & 1.01 \\
$u$ & 0.00073 & 0.00069 & 0.054 & 0.057 \\
$\theta$ & 0.021 & 0.016 & 0.31 & 0.38 \\
\hline
\end{tabular}

Source: authors' calculations.

Figure 2 also shows the equivalent simulation results when agents learn the REE with decreasing gain, with initial estimates of the PLM parameters as described above. It shows the path of these parameter estimates as agents learn from their forecast errors. The key result is that convergence is very slow, when agents are given a relatively small amount of historical data (12.5 years) and with initial estimates of the model parameters not unrealistically far from the true REE values. As shown in Appendix Figure C2, this takes thousands of years despite being exponential. This indicates that under adaptive learning, an economy could be persistently away from its REE level of unemployment, on the high or low side, even though agents are behaving rationally in the limited sense prescribed by the 'good econometrician.' In this sense, RE can be a poor approximation in terms of levels to a model with learning. One recommendation from this result is that when calibrating the Mortensen-Pissarides model, targeting second moments of the data should always be preferable, whereas not exactly hitting levels of the endogenous variables may not be too concerning.

As a further example, in Appendix C3 we simulate the model with no memory, and allow the agents to have guessed the correct initial parameter estimates, $x_{0}=x_{R E E}$, but 
Figure 2: Simulations of the labour market model and agents' parameter estimates: a comparison of the REE, decreasing gain and constant gain learning
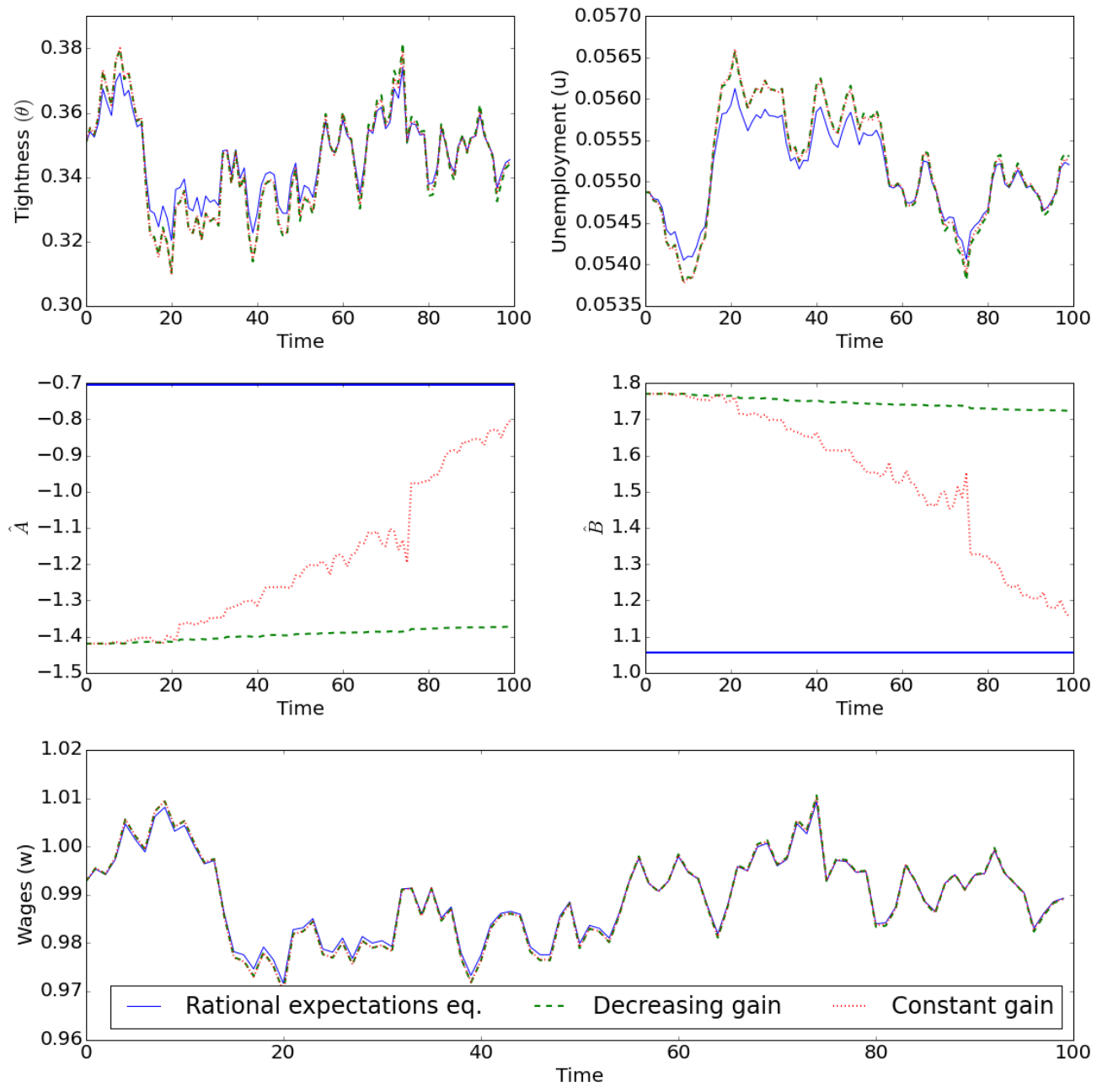

Note.- initial parameter estimates of the PLM, and $\hat{B}_{0}$ is assumed to be 'realistically' far away from the true REE values, whereas $\hat{A}_{0}$ is chosen such that under learning the economy begins at $\bar{\theta}$.

suppose that there is an immediate negative twenty percent shock to the flow value of unemployment $b$. In the REE, due to the rise in the surplus of a match, firms immediately open more vacancies, and the unemployment rate falls. Under learning, the initial increase in $\theta$ is smaller. Therefore, unemployment falls more slowly as agents attempt to disentangle the effects of the structural shock from the stochastic process. In this sense, 
the response to the shock under learning leads to a less volatile path for unemployment. If actual labour market data contain the effects of frequent structural shocks of this kind, then econometric learning will not improve the ability of the standard search model to match their cyclical properties.

\subsection{Speed of convergence}

As shown theoretically in Benveniste et al. (2012), the learning of the agents results in root-t convergence to the true REE parameter estimates if all the eigenvalues of the system's Jacobian have a real part strictly less than a half. ${ }^{18}$ Here this requires $\psi_{2}<1 / 2$. In the example parametrisation above this is not ensured, with $\psi_{2}=0.57$. More generally, it can be shown with simulations that the speed of convergence decreases substantially as $\psi_{2} \rightarrow 1$, the threshold for E-Stability. To illustrate a decrease in the speed of convergence, in Appendix Figure $\mathrm{C} 4$ we consider a value of $\psi=0.91$ by decreasing worker bargaining power to $\beta=0.1$, keeping all other parameters except $c$ constant, which is always used to match the mean value of $\theta$ from the UK data. As expected, the rate of convergence decreases, and the economy remains more persistently away from the REE. As such, choosing parameter values which guarantee a higher speed of convergence is one way in which the REE model could become an improved approximation of an alternative with econometric learning.

\subsection{Constant gain learning}

In Figure 2 we also compare the results of our first simulation with decreasing gain learning to an equivalent example with constant gain parameter $\gamma=0.05 .{ }^{19}$ When agents weight recent data more, convergence to the REE is faster, and agents' parameter estimates are more volatile. This faster convergence results in more volatile series of labour market tightness, wages and unemployment. However, the gain parameter generating this faster convergence roughly implies that agents only use data over the past twenty quarters to update their beliefs, and is notably outside the range suggested by the adaptive learning literature (see Di Pace et al. (2016) for a discussion). Our simulation results with constant gain learning and more reasonable levels of memory weighting are not dissimilar to those obtained with decreasing gain.

\footnotetext{
${ }^{18}$ I.e. the rate of convergence at which in classical econometrics the mean of the least squares parameter estimate converges to the true value.

${ }^{19}$ For constant gain learning there is no analytic solution for expectational stability and so we must select a reasonably small gain parameter to ensure convergence.
} 


\subsection{An alternative non-steady-state perceived law of motion}

So far we have described a model of econometric learning in which agents endeavour to forecast labour market tightness $\theta$. However this is a construct of the model and its assumptions. It is an attractive feature of the search and matching models that the equilibrium can be described by this single choice variable, determined by the state of the productivity process, but independent of unemployment. But firms in the model are described as choosing the number of vacancies to post, or analogously whether or not to enter the labour market. And for given levels of $\theta$ and productivity, this choice does depend on the state of the labour market. In the REE, if we consider the economy as initially being at some steady state (i.e. unemployment and vacancy rates are on the Beveridge curve), then in moving to any new steady state the vacancy rate changes non-monotonically. In characterising agents as learning how to choose and forecast $\theta$, we imply that they fully understand the non-steady-state dynamics of the model. Here we consider the implications of relaxing this assumption (for what follows, see Appendix A.6 for complete derivations and descriptions of parameter values).

Linearising (14), (20) and (12) around the steady-state deterministic values of vacancies, employment and output per worker, we derive an alternative system defining the economy:

$$
\begin{aligned}
& v_{t}=\kappa_{0}+\kappa_{1} y_{t+1}^{e}+\kappa_{2} v_{t+1}^{e}+\kappa_{3} n_{t+1}^{e}+\kappa_{4} n_{t}, \\
& n_{t}=\phi_{0}+\phi_{1} n_{t-1}+\phi_{2} v_{t-1}, \\
& y_{t}=(1-\rho)+\rho y_{t-1}+\varepsilon_{t} .
\end{aligned}
$$

We endow agents with a PLM in which they use both the output per worker and employment states to forecast vacancy creation,

$$
v_{t}=\hat{A}_{t}+\hat{B}_{t} y_{t}+\hat{C}_{t} n_{t-1} .
$$

Given (38)-(41), we can then derive the ALM for this version of the economy, and subsequently a $\tilde{T}$-mapping

$$
\tilde{T}\left(\hat{A}_{t}, \hat{B}_{t}, \hat{C}_{t}\right)=\left(\tilde{\kappa}_{0}+\tilde{\kappa}_{2}\left[\hat{A}_{t}+(1-\rho) \hat{B}_{t}\right], \tilde{\kappa}_{1}+\tilde{\kappa}_{2} \rho \hat{B}_{t}, \tilde{\kappa}_{3}+\tilde{\kappa}_{2} \hat{C}_{t}\right) .
$$

Assuming agents update their parameter estimates for the PLM using RLS as previously, and applying the same E-stability principle, it can be shown that the sufficient condition to guarantee local convergence to the REE is given by $\tilde{\kappa}_{2}<1$. Comparing this with 
the condition for stability of the MSV-PLM, $\tilde{\kappa}_{2} \geq \psi_{2}$. Hence, convergence to the REE is slower when agents do not implicitly know the out of steady-state dynamics of employment and vacancy creation. The REE model is then a poorer approximation to an economy with econometric learning. What is more, for a subset of parameter values we cannot claim that the model is E-stable. For example, it is less likely to be E-stable in the circumstance of inefficiently high vacancy creation, departing from the Hosios (1990) condition (i.e. $\alpha>\beta$ ). Though for the parametrisation we have used here the model would still certainly converge to the REE.

\section{Conclusion}

We take the textbook linearised RBC version of the model of search and matching frictions for the labour market and show that the unique REE is not only always E-stable, for all well-defined sets of parameter values, but this result is robust to overparametrisation of the MSV-PLM used by agents (Strong E-stability) with decreasing gain learning. These local convergence conditions also extend trivially to global convergence. Because the economy will eventually move to the REE when agents use econometric learning, the potentially unrealistic RE assumption in this class of model is nonetheless reasonable. We use recent UK data to parametrise the model, and show that although the model is E-stable, implied convergence can be very slow. Therefore, the RE model of unemployment fluctuations could in fact be a poor approximation to an economy in which agents more realistically learn as econometricians, especially in the presence of frequent structural or permanent shocks. The MSV-PLM implicitly assumes that agents understand the out of steady-state paths of employment and vacancy creation in the model. When we consider a version of the PLM which relaxes this assumption, we see that convergence is further slowed, and local E-stability of the model is not guaranteed, making the approximation of the RE model even weaker. 


\section{Bibliography}

Andolfatto, D., March 1996. Business Cycles and Labor-Market Search. American Economic Review $86(1), 112-132$.

Benhabib, J., Farmer, R. E., 1999. Indeterminacy and sunspots in macroeconomics. In: Taylor, J. B., Woodford, M. (Eds.), Handbook of Macroeconomics. Vol. 1 of Handbook of Macroeconomics. Elsevier, Ch. 6 , pp. 387-448.

Benveniste, A., Métivier, M., Priouret, P., 2012. Adaptive algorithms and stochastic approximations. Vol. 22. Springer Science \& Business Media.

Berardi, M., Galimberti, J. K., 2012. On the plausibility of adaptive learning in macroeconomics: A puzzling conflict in the choice of the representative algorithm. Centre for Growth and Business Cycle Research Discussion Paper Series 177, The Univeristy of Manchester.

Berardi, M., Galimberti, J. K., 2013. A note on exact correspondences between adaptive learning algorithms and the Kalman filter. Economics Letters 118 (1), 139-142.

Blanchard, O., Watson, M. W., 1983. Bubbles, Rational Expectations and Financial Markets. NBER Working Papers 0945, National Bureau of Economic Research.

Borowczyk-Martins, D., Jolivet, G., Postel-Vinay, F., July 2013. Accounting For Endogeneity in Matching Function Estimation. Review of Economic Dynamics 16 (3), 440-451.

Branch, W., McGough, B., 2016. Heterogeneous beliefs and trading inefficiencies. Journal of Economic Theory 163 (C), 786-818.

Bullard, J., Mitra, K., September 2002. Learning about monetary policy rules. Journal of Monetary Economics 49 (6), 1105-1129.

Burgess, S., Turon, H., April 2010. Worker flows, job flows and unemployment in a matching model European Economic Review 54 (3), 393-408.

Carceles-Poveda, E., Giannitsarou, C., August 2007. Adaptive learning in practice. Journal of Economic Dynamics and Control 31 (8), 2659-2697.

Di Pace, F., Mitra, K., Zhang, S., Dec. 2016. Adaptive learning and labour market dynamics. Bank of England working papers 633, Bank of England.

Eusepi, S., Preston, B., October 2011. Expectations, Learning, and Business Cycle Fluctuations. American Economic Review 101 (6), 2844-2872.

Evans, G., Honkapohja, S., 1986. A Complete Characterization of ARMA Solutions to Linear Rational Expectations Models. Review of Economic Studies 53 (2), 227-239.

Evans, G. W., Honkapohja, S., 1998. Economic Dynamics with Learning: New Stability Results. Review of Economic Studies 65 (1), 23-44.

Evans, G. W., Honkapohja, S., 2001. Learning and expectations in macroeconomics. Frontiers of economic research. Princeton University Press, Princeton, NJ.

Hagedorn, M., Manovskii, I., 2008. The cyclical behavior of equilibrium unemployment and vacancies revisited. American Economic Review 98 (4), 1692-1706.

Hosios, A., 1990. On The Efficiency of Matching and Related Models of Search and Unemployment. Review of Economic Studies 57 (2), 279-298.

Kreps, D. M., 1998. Anticipated utility and dynamic choice. Econometric Society Monographs 29, 242 274.

Kurozumi, T., Van Zandweghe, W., 2012. Learning about monetary policy rules when labor market search and matching frictions matter. Journal of Economic Dynamics and Control 36 (4), 523-535.

Mankiw, N. G., Reis, R., Wolfers, J., 2004. Disagreement about inflation expectations. In: NBER Macroeconomics Annual 2003, Volume 18. The MIT Press, Cambridge, MA, pp. 209-270.

Marcet, A., Sargent, T. J., 1989. Convergence of least squares learning mechanisms in self-referential linear stochastic models. Journal of Economic Theory 48 (2), 337-368.

McCallum, B. T., 1983. On non-uniqueness in rational expectations models: An attempt at perspective. Journal of Monetary Economics 11 (2), 139-168. 
Merz, M., November 1995. Search in the labor market and the real business cycle. Journal of Monetary Economics 36 (2), 269-300.

Milani, F., October 2007. Expectations, learning and macroeconomic persistence. Journal of Monetary Economics 54 (7), 2065-2082.

Milani, F., 2011. Expectation Shocks and Learning as Drivers of the Business Cycle. Economic Journal 121 (552), 379-401.

Mortensen, D. T., Pissarides, C. A., 1994. Job Creation and Job Destruction in the Theory of Unemployment. Review of Economic Studies 61 (3), 397-415.

Pfajfar, D., Santoro, E., September 2010. Heterogeneity, learning and information stickiness in inflation expectations. Journal of Economic Behavior \& Organization 75 (3), 426-444.

Pissarides, C. A., 2000. Equilibrium unemployment theory. The MIT Press, Cambridge, MA.

Pissarides, C. A., Petrongolo, B., 2001. Looking into the Black Box: A Survey of the Matching Function Journal of Economic Literature 39 (2), 390-431.

Rogerson, R., Shimer, R., 2011. Search in Macroeconomic Models of the Labor Market. In: Ashenfelter, O., Card, D. (Eds.), Handbook of Labor Economics. Vol. 4, Part A. Elsevier, pp. 619-700.

Shimer, R., March 2005. The Cyclical Behavior of Equilibrium Unemployment and Vacancies. American Economic Review 95 (1), 25-49.

Smith, J. C., 05 2011. The Ins and Outs of UK Unemployment. Economic Journal 121 (552), 402-444. 


\section{Appendix A. Methodology}

\section{Appendix A.1. Linearisation}

We take a first order Taylor approximation around the deterministic steady-state values of $\theta$ and $y, \bar{\theta}$ and $\bar{y}=1$ respectively, approximating the right and the left hand side of equation (20) which is stated here again for convenience,

$$
\frac{c}{\delta q\left(\theta_{t}\right)}=\left[(1-\beta)\left(y_{t+1}-b\right)+\frac{(1-\lambda) c}{q\left(\theta_{t+1}\right)}-\theta_{t+1} \beta c\right]^{e} .
$$

This results in

$$
\begin{aligned}
\frac{c}{\delta q(\bar{\theta})}-\frac{c q^{\prime}(\bar{\theta})}{\delta[q(\bar{\theta})]^{2}}\left(\theta_{t}-\bar{\theta}\right)= & (1-\beta)(\bar{y}-b)+(1-\beta)\left(y_{t+1}^{e}-\bar{y}\right) \\
& -\bar{\theta} \beta c-\beta c\left(\theta_{t+1}^{e}-\bar{\theta}\right)+\frac{(1-\lambda) c}{q(\bar{\theta})} \\
& -\frac{(1-\lambda) c q^{\prime}(\bar{\theta})}{[q(\bar{\theta})]^{2}}\left(\theta_{t+1}^{e}-\bar{\theta}\right) .
\end{aligned}
$$

By noting that

$$
\frac{c}{\delta q(\bar{\theta})}=(1-\beta)(\bar{y}-b)+\frac{(1-\lambda) c}{q(\bar{\theta})}-\bar{\theta} \beta c
$$

must hold in equilibrium according to (20), this steady-state condition can be subtracted from both sides of the approximated equation. Then solving explicitly for $\theta_{t}$ and defining the functional form $q(\bar{\theta})=\mu \bar{\theta}^{-\alpha}$, (A.1) becomes

$$
\begin{aligned}
\theta_{t} & =\left\{1+\frac{\beta \delta \mu^{2}(\bar{\theta})^{-2 \alpha}}{\alpha \mu(\bar{\theta})^{-\alpha-1}}-(1-\lambda) \delta\right\} \bar{\theta} \\
& -\frac{(1-\beta) \delta \mu^{2}(\bar{\theta})^{-2 \alpha}}{c \alpha \mu(\bar{\theta})^{-\alpha-1}} \bar{y} \\
& +\frac{(1-\beta) \delta \mu^{2}(\bar{\theta})^{-2 \alpha}}{c \alpha \mu(\bar{\theta})^{-\alpha-1}} y_{t+1}^{e} \\
& +\left\{-\frac{\beta \delta \mu^{2}(\bar{\theta})^{-2 \alpha}}{\alpha \mu(\bar{\theta})^{-\alpha-1}}+(1-\lambda) \delta\right\} \theta_{t+1}^{e},
\end{aligned}
$$


which can be simplified to the form given in the text, (21), with coefficients

$$
\begin{aligned}
& \psi_{0}=\left[1-\psi_{2}\right] \bar{\theta}-\psi_{1} \bar{y}, \\
& \psi_{1}=\frac{(1-\beta) \delta \bar{\theta} q(\bar{\theta})}{c \alpha}, \\
& \psi_{2}=\delta\left[(1-\lambda)-\frac{\beta \bar{\theta} q(\bar{\theta})}{\alpha}\right],
\end{aligned}
$$

and with the steady-state value for labour market tightness the solution to

$$
(1-\beta)(\bar{y}-b)-\frac{c\left(\frac{1-\delta}{\delta}+\lambda\right)}{q(\bar{\theta})}-\beta c \bar{\theta}=0 .
$$

Appendix A.2. Determinacy of the REE

The operator $E_{t}$ denotes mathematical expectations formed at period $t$. The linearised dynamics of output (22) can be substituted into (21) by noting under RE that $E_{t} y_{t+1}=(1-\rho)+\rho y_{t}$;

$$
\theta_{t}=\tilde{\psi}_{0}+\tilde{\psi}_{1} y_{t-1}+\tilde{\psi}_{2} E_{t}^{*} \theta_{t+1}+\tilde{\psi}_{1} \rho^{-1} \varepsilon_{t},
$$

with

$$
\begin{aligned}
& \tilde{\psi}_{0}=\psi_{0}+\psi_{1}(1-\rho)(1+\rho), \\
& \tilde{\psi}_{1}=\psi_{1} \rho^{2}, \\
& \tilde{\psi}_{2}=\psi_{2} .
\end{aligned}
$$

A REE of the system (22) and (A.3) is a stochastic process for $\theta_{t}$ that satisfies this system with $E_{t} \theta_{t+1}=\theta_{t+1}^{e}$. To see this possibility, note that (A.3) can be written in $\operatorname{ARMA}(1,1)$ form by iterating (A.3) forward by one period, and subsequently comparing this to the result one obtains by solving (A.3) for $\theta_{t+1}^{e}$. This gives

$$
\begin{aligned}
\theta_{t}= & \tilde{\psi}_{2}^{-1}\left(\rho^{-1} \tilde{\psi}_{1}(1-\rho)-\tilde{\psi}_{0}\right)-\tilde{\psi}_{1} \tilde{\psi}_{2}^{-1} \rho^{-1} y_{t-1} \\
& +\tilde{\psi}_{2}^{-1} \theta_{t-1}+d_{1} \varepsilon_{t}+d_{2} \eta_{t},
\end{aligned}
$$

with $d_{1}$ and $d_{2}$ being arbitrary parameters, and $\eta_{t}:=E_{t}\left[\theta_{t+1}\right]-E_{t-1}\left[\theta_{t+1}\right]$ being a martingale difference sequence with $E_{t}\left[\eta_{t+1}\right]=0$ by the law of iterated expectations. No restrictions are imposed on $d_{1}$ or $d_{2}$, since RE formed according to (A.4) regarding $\theta_{t+1}$ are unaffected by those parameters. Therefore there is a continuum of possible solutions 
to (A.4). Evans and Honkapohja (1986) have shown that any finite degree ARMA solution of an equation in the form of (A.3) can at most be ARMA(1,1), and the particular form of (A.4) nests all possible ARMA solutions of finite degree. The ARMA class of solutions is stable if $\left|\psi_{2}\right|>1$, and is unstable for $\left|\psi_{2}\right|<1$.

. In this case the solution to (21) and (22) is the fundamental or minimal-statevariable (MSV) solution; it is impossible to delete any state variable from the minimum set and still obtain solutions to (22) and (A.3) for all permitted parameter values (McCallum, 1983). The MSV solution here is guessed to be

\section{Appendix A.3. ARMA $(1,1)$ and the MSV solution}

Derivation of MSV solution: (A.4) can be re-written as

$$
\theta_{t}=\frac{\rho \tilde{\psi}_{0}-\tilde{\psi}_{1}(1-\rho)}{\rho\left(1-\tilde{\psi}_{2}\right)}+\frac{\tilde{\psi}_{1}}{\rho\left(L-\tilde{\psi}_{2}\right)} y_{t-1}-\frac{d_{1} \tilde{\psi}_{2}}{\left(L-\tilde{\psi}_{2}\right)} \varepsilon_{t}-\frac{d_{2}}{\left(L-\tilde{\psi}_{2}\right)} \eta_{t}
$$

with $L$ denoting the lag operator such that $L x_{t}=x_{t-1}$. The parameters $d_{1}$ and $d_{2}$ can be chosen arbitrarily. In particular, to obtain the MSV solution $\theta_{t}=A+B y_{t-1}+C \varepsilon_{t}$ one must first set $d_{2}=0$. (A.5) can be re-written as:

$$
\begin{gathered}
\theta_{t}=\frac{\rho \tilde{\psi}_{0}-\tilde{\psi}_{1}(1-\rho)}{\rho\left(1-\tilde{\psi}_{2}\right)}-\left(\rho^{-1} \tilde{\psi}_{1} y_{t-1}-d_{1} \tilde{\psi}_{2} \varepsilon_{t}\right) \sum_{i=1}^{\infty} \tilde{\psi}_{2}^{-i} L^{i-1} . \\
\theta_{t}=\frac{\rho \tilde{\psi}_{0}-\tilde{\psi}_{1}(1-\rho)}{\rho\left(1-\tilde{\psi}_{2}\right)}+\rho^{-1} \tilde{\psi}_{1} \tilde{\psi}_{2}^{-1}(1-\rho) \sum_{i=1}^{\infty}\left(\sum_{j=1}^{i} \rho^{-j}\right) \tilde{\psi}_{2}^{-i}-\rho^{-1} \tilde{\psi}_{1} \tilde{\psi}_{2}^{-1} y_{t-1} \sum_{i=0}^{\infty}(\rho \tilde{\psi})^{-i} \\
+\varepsilon_{t-1}\left(\rho^{-1} \tilde{\psi}_{1} \tilde{\psi}_{2}^{-1} \sum_{i=1}^{\infty}\left(\sum_{j=1}^{i} \rho^{-j} L^{i-j}\right) \tilde{\psi}_{2}^{-i}+d_{1} \sum_{i=1}^{\infty} \tilde{\psi}_{2}^{-i} L^{i-1}\right)+d_{1} \varepsilon_{t} .
\end{gathered}
$$

Therefore, to derive an MSV solution from a broader the class of ARMA(1,1) solutions, in which no lags of $\varepsilon_{t}$ can remain, we therefore see from (A.6) that

$$
\begin{aligned}
d_{1} & =-\frac{\tilde{\psi}_{1}}{\rho \tilde{\psi}_{2}}\left(\frac{1}{\rho \tilde{\psi}_{2}}+\left(\frac{1}{\rho \tilde{\psi}_{2}}\right)^{2}+\left(\frac{1}{\rho \tilde{\psi}_{2}}\right)^{3}+\ldots\right), \\
& =\frac{\tilde{\psi}_{1}}{\rho \tilde{\psi}_{2}\left(1-\rho \tilde{\psi}_{2}\right)} \quad \text { if } \quad \tilde{\psi}_{2}>\frac{1}{\rho}>1,
\end{aligned}
$$

which corresponds to the condition for stable $\operatorname{ARMA}(1,1)$ solutions. Otherwise, the MSV solution cannot be derived from the class of unstable $\operatorname{ARMA}(1,1)$ solutions, and is instead the only stable solution. 
The REE values of the parameters $A, B$, and $C$ are found using the method of undetermined coefficients:

$$
\begin{aligned}
A & =\frac{\tilde{\psi}_{0}}{1-\tilde{\psi}_{2}}+\frac{\tilde{\psi}_{1} \tilde{\psi}_{2}(1-\rho)}{\left(1-\tilde{\psi}_{2}\right)\left(1-\tilde{\psi}_{2} \rho\right)}, \\
B & =\frac{\tilde{\psi}_{1}}{1-\tilde{\psi}_{2} \rho}, \\
C & =B \rho^{-1}
\end{aligned}
$$

where we have assumed that $\tilde{\psi}_{2} \neq 1$ and $\tilde{\psi}_{2} \rho \neq 1$.

\section{Appendix A.4. Global convergence}

Given the model discussed here has a unique equilibrium, and satisfies the assumptions of Evans and Honkapohja (1998) that guarantee global convergence, we simply apply their Theorem 2 to the recursive learning algorithm given by (29) and (31).

For $R_{t}$, using $E z_{t} z_{t}^{\prime}=M_{z}$, where $M_{z}$ is some positive definite matrix, taking expectations we have the ODE,

$$
\frac{d R}{d \tau}=M_{z}-R
$$

which is globally asymptotically stable and independent of $x_{t}$.

It is possible that for some $t R_{t}$ may not be invertible, though this will happen only a finite number of times with probability 1 . We modify the algorithm for $x_{t}$ to

$$
x_{t}=x_{t-1}+t^{-1} u\left(R_{t}\right) z_{t-1}\left\{z_{t-1}^{\prime}\left[T\left(\hat{A}_{t}, \hat{B}_{t}\right)-x_{t-1}\right]+\eta_{t}\right\},
$$

where $u(R)$ is a bounded regular function from the space of $2 \times 2$ matrices to the subspace of positive definite matrices such that $u(R)=R^{-1}$ in the neighbourhood of $M_{z}$. Then taking expectations the ODE is given by

$$
\begin{aligned}
\frac{d x}{d \tau} & =u(R) M_{z}(T(\hat{A}, \hat{B})-(A, B))^{\prime} \\
& =u(R) M_{z}\left(\psi_{2}-1\right)((\hat{A}, \hat{B})-(A, B))^{\prime}
\end{aligned}
$$

Given that the other requirements of the theorem are trivially satisfied, then it applies, and this differential equation is clearly globally asymptotically stable for $\psi_{2}<1$, and this stability is exponential; $(\hat{A}, \hat{B}) \rightarrow(A, B)$ globally almost surely. 


$$
\begin{gathered}
\theta_{t}=\frac{\tilde{\psi}_{0}+\tilde{\psi}_{2}\left(a+b_{1}(1-\rho)\right)}{1-\tilde{\psi}_{2} c_{1}}+\frac{\tilde{\psi}_{1}+\tilde{\psi}_{2}\left(b_{2}+b_{1} \rho\right)}{1-\tilde{\psi}_{2} c_{1}} y_{t-1}+\frac{\tilde{\psi}_{2}\left(b_{1}+d_{1}\right)+\tilde{\psi}_{1} \rho^{-1}}{1-\tilde{\psi}_{2} c_{1}} \varepsilon_{t} \\
+\frac{\tilde{\psi}_{2} f_{1}}{1-\tilde{\psi}_{2} c_{1}} \eta_{t}+\frac{\tilde{\psi}_{2}}{1-\tilde{\psi}_{2} c_{1}} \sum_{j=3}^{s} b_{j} y_{t+1-j}+\frac{\tilde{\psi}_{2}}{1-\tilde{\psi}_{2} c_{1}} \sum_{j=2}^{r} c_{j} \theta_{t+1-j} \\
+\frac{\tilde{\psi}_{2}}{1-\tilde{\psi}_{2} c_{1}} \sum_{j=2}^{q} d_{j} \varepsilon_{t+1-j}+\frac{\tilde{\psi}_{2}}{1-\tilde{\psi}_{2} c_{1}} \sum_{j=2}^{l} f_{j} \eta_{t+1-j}
\end{gathered}
$$

This defines again a T-mapping from the PLM to the ALM with corresponding elements:

$$
\begin{aligned}
a & =\frac{\tilde{\psi}_{0}+\tilde{\psi}_{2}\left(a+b_{1}(1-\rho)\right)}{1-\tilde{\psi}_{2} c_{1}}, \\
b_{1} & =\frac{\tilde{\psi}_{1}+\tilde{\psi}_{2}\left(b_{1} \rho+b_{2}\right)}{1-\tilde{\psi}_{2} c_{1}}, \\
d_{0} & =\frac{\tilde{\psi}_{1} \rho^{-1}+\tilde{\psi}_{2}\left(b_{1}+d_{1}\right)}{1-\tilde{\psi}_{2} c_{1}}, \\
b_{j} & =\frac{\tilde{\psi}_{2}}{1-\tilde{\psi}_{2} c_{1}} b_{j+1}, \quad j=2, \ldots, s-1, \quad b_{s}=0, \\
c_{j} & =\frac{\tilde{\psi}_{2}}{1-\tilde{\psi}_{2} c_{1}} c_{j+1}, \quad j=1, \ldots, r-1, \quad c_{r}=0, \\
d_{j} & =\frac{\tilde{\psi}_{2}}{1-\tilde{\psi}_{2} c_{1}} d_{j+1}, \quad j=1, \ldots, q-1, \quad d_{q}=0, \\
f_{j} & =\frac{\tilde{\psi}_{2}}{1-\tilde{\psi}_{2} c_{1}} f_{j+1}, \quad j=0, \ldots, l-1, \quad f_{l}=0 .
\end{aligned}
$$

Since (A.14) - (A.20) describes a non-linear system of differential equations, we first have to linearise (36) to study stability properties. However, the subsystem (A.18) is independent of the other equations and can be analysed separately. The eigenvalues of the Jacobian of $T(\mathbf{c})-\mathbf{c}$ at the REE values $c_{j}=0$ for $j=1, \ldots, r$ are found to be $r$ times repeatedly equal to -1 and therefore the subsystem (A.18) will converge towards the REE values. Due to the convergence of $\mathbf{c}$ it is apparent that $\mathbf{d}$ (apart from $d_{0}$ ) and $\mathbf{f}$ will also converge to their REE values of vectors of zeros. Moreover, $b_{j}=0$ for $j=2, \ldots, s$ is easily verified to be the values towards which the economy under learning converges. Finally, convergence of $a, b_{1}$ and $d_{0}$ are studied by analysing the Jacobian of the system (A.14)-(A.16). If this Jacobian has eigenvalues strictly less than unity, then the whole system is E-stable. It can easily be verified that the eigenvalues are $\psi_{2}$ and $\psi_{2} \rho$. 
Appendix A.6. A non-steady-state PLM

The system defined as (38)-(40), linearised around steady-state values $\bar{v}, \bar{n}, \bar{y}=1$ has derived parameter values as follows,

$$
\begin{aligned}
\kappa_{0} & =\left(1-\kappa_{2}\right) \bar{\theta}-\bar{y} \kappa_{1}, \\
\kappa_{1} & =\frac{\delta(1-\beta)(1-\bar{n}) \bar{\theta} q(\bar{\theta})}{c \alpha}, \\
\kappa_{2} & =\delta\left[(1-\lambda)-\frac{\beta \bar{\theta} q(\bar{\theta})}{\alpha}\right] \quad\left(=\psi_{2}\right), \\
\kappa_{3} & =\bar{\theta} \kappa_{2}, \\
\kappa_{4} & =-\bar{\theta} \\
\phi_{0} & =\alpha q(\bar{\theta})(\bar{v}+\bar{\theta} \bar{n}), \\
\phi_{1} & =(1-\lambda)-\alpha \theta q(\bar{\theta}), \\
\phi_{2} & =q(\bar{\theta})(1-\alpha) .
\end{aligned}
$$

Given the PLM (41), agents form expectations according to

$$
v_{t+1}^{e}=\hat{A}_{t}+\hat{B}_{t}\left[(1-\rho)+\rho y_{t}\right]+\hat{C}_{t} n_{t}
$$

and the ALM is given by

$$
v_{t}=\tilde{\kappa}_{0}+\tilde{\kappa}_{2}\left[\hat{A}_{t}+(1-\rho) \hat{B}_{t}\right]+\left[\tilde{\kappa}_{1}+\tilde{\kappa}_{2} \rho \hat{B}_{t}\right] y_{t}+\left[\tilde{\kappa}_{3}+\tilde{\kappa}_{2} \hat{C}_{t}\right] n_{t}
$$

where

$$
\begin{aligned}
\tilde{\kappa}_{0} & =\frac{\kappa_{0}+\kappa_{1}(1-\rho)+\kappa_{3} \phi_{0}}{1-\kappa_{3} \phi_{2}}, \\
\tilde{\kappa}_{1} & =\frac{\kappa_{1} \rho}{1-\kappa_{3} \phi_{2}}, \\
\tilde{\kappa}_{2} & =\frac{\kappa_{2}}{1-\kappa_{3} \phi_{2}} \\
\tilde{\kappa}_{3} & =\frac{\kappa_{4}+\kappa_{3} \phi_{1}}{1-\kappa_{3} \phi_{2}}
\end{aligned}
$$

Given the mapping $\tilde{T}$ defined in the main text, the REE is E-stable if all the eigenvalues of the Jacobian of $\tilde{T}(\hat{A}, \hat{B}, \hat{C})-(\hat{A}, \hat{B}, \hat{C})$ have negative real parts. Thus, we must have

$$
\tilde{\kappa}_{2} \rho-1<0
$$


and

$$
\tilde{\kappa}_{2}-1<0,
$$

whereby the second condition implies the validity of the first. Therefore, we need to check for what range of parameter values of the model the second condition is true. Writing out the term $\tilde{\kappa}_{2}$ and rearranging, we see that the required condition is

$$
\delta\left[(1-\lambda)-\frac{\beta \bar{\theta} q(\bar{\theta})}{\alpha}\right][1+\bar{\theta} q(\bar{\theta})(1-\alpha)]<1,
$$

or

$$
\psi_{2}[1+\bar{\theta} q(\bar{\theta})(1-\alpha)]<1 .
$$

Given that $\tilde{\kappa}_{2} \geq \psi_{2}$, if the E-stability condition holds with this alternative PLM, then convergence will be slower. For the complete range of possible model parameters, this condition does not hold. As realistic levels of $\lambda$ are small, the condition would be sensitive to assumed parameter values of $\beta$ and $\alpha$. For example, given $\alpha>\beta>0$, which is the case of low worker bargaining power, whereby wages are reduced towards the value of the outside option, and there is excessive firm entry, or inefficiently high according to the Hosios (1990) condition, it is more likely E-stability will not hold. 


\section{Appendix B. Parametrisation of the model}

We normalise average productivity to be one. For the productivity process we estimate an $\mathrm{AR}(1)$ in log deviations from trend output per worker, dynamically de-trended using the HP filter with standard quarterly smoothing parameter, and find an autoregressive parameter $\rho$ for the period of 0.84 , and a standard deviation for the shocks $\sigma_{\varepsilon}$ of 0.0063 (assuming them to be normally distributed). For the labour market, we parametrise the model to the unemployment rate, measured as the fraction of the economically active population aged 16 and over who are ILO unemployed. We use official quarterly time series from Office for National Statistics (ONS) Labour Market Statistics. For transition rates between labour market states we use the flows time series similarly published by ONS, which are derived from the Two-quarter Longitudinal Labour Force Survey and are consistent with all stocks series. The economy we describe has two states. In reality there is a third: economic inactivity. To adhere to our interpretation of $u_{t}$ as the unemployment rate, abstracting from the relative size of the inactive population over the business cycle, as is common in the literature (Shimer, 2005; Hagedorn and Manovskii, 2008), we must carefully construct from the raw data measures of job finding and separation rates. In the notation of the model, the steady-state unemployment rate is given by

$$
u_{t}^{*}=\frac{\lambda}{\lambda+\theta_{t} q\left(\theta_{t}\right)} .
$$

As per Smith (2011), using three-state flows data between the stocks in employment, unemployment and inactivity, denoted by $\{E, U, I\}$, with transition rates, for example between inactivity and unemployment, denoted by $p_{I U_{t}}$, we can re-write (B.1) as

$$
u_{t}^{*}=\underbrace{\frac{p_{E U_{t}}+\frac{p_{E I_{t}} p_{I U_{t}}}{p_{I U_{t}}+p_{I E_{t}}}}{p_{E U_{t}}+\frac{p_{E I_{t}} p_{I U_{t}}}{p_{I U_{t}}+p_{I E_{t}}}}+\underbrace{p_{U E_{t}}+\frac{p_{U I_{t}} p_{I E_{t}}}{p_{I U_{t}}+p_{I E_{t}}}}_{\theta_{t} q\left(\theta_{t}\right)}}_{\lambda_{t}} .
$$

As such, the separation rate from real data which is consistent with the model described here is the sum of the direct transition rate from employment to unemployment and a term which captures the indirect role of transitions to unemployment via inactivity with a similar interpretation for the job finding rate.

Using this measure of the hiring rate from the transition rates data, we estimate the parameters of the aggregate matching function using least squares as follows for 2002q1- 
13q2:

$$
\log \left(p_{U E_{t}}+\frac{p_{U I_{t}} p_{I E_{t}}}{p_{I U_{t}}+p_{I E_{t}}}\right)=\log (\mu)+(1-\alpha) \log \left(\frac{v_{t}}{u_{t}}\right)+\zeta_{t}
$$

where data for $v_{t}$ come from the quarterly ONS aggregate vacancies series, and $u_{t}$ is the UK national unemployment rate. Following Borowczyk-Martins et al. (2013), we consider time trends in the estimation to account for the endogeneity of unobserved shifts in the matching efficiency with the number of vacancies that firms open, but these all drop out. We also carry out tests that the matching function is Cobb-Douglas, and reject the alternative. In line with the existing literature, we find that the data suggests the matching function has decreasing returns to scale, although we proceed as though it is constant (see Pissarides and Petrongolo (2001) for a thorough review of estimates of the aggregate matching function). We find estimates of $\alpha=0.67$ and $\mu=0.56$. For the constant separation rate parameter in the model, over the same period we choose an average value of the two-quarter composite hazard rate: $p_{E U}+\frac{p_{E I} p_{I U}}{p_{I U}+p_{I E}}=\lambda=0.023$. (In practice we regress the data on a constant and cubic trend to account for low frequency shifts for the short period in question, then selecting the estimated constant as the parameter value - we similarly do this when estimating moments of the labour market variables presented in Table 2). The discount factor is set as $\delta=0.99$, and to restrict the number of free parameters we let the bargaining power adhere to the Hosios (1990) condition, $\beta=\alpha=0.67$. We set the flow value of unemployment to 0.8 . How to select or estimate appropriate values of both the bargaining power and the flow value of unemployment are open to debate. Shimer (2005) and subsequently Hagedorn and Manovskii (2008) are often considered in the literature as more extreme examples for parametrisations, and highlight how this affects the ability of the model to match the observed volatility of unemployment and vacancy creation. With the relatively arbitrary parametrisation applied here, we are somewhere in between these two examples. The remaining parameter, the flow vacancy cost $c$, is chosen to match the observed level of average labour market tightness over the period, as displayed in Table 2 and as used to estimate the parameters of the matching function. 


\section{Appendix C. Additional figures}

Figure C1: Simulation of the equilibrium of the stochastic model with the assumption of rational expectations: the REE
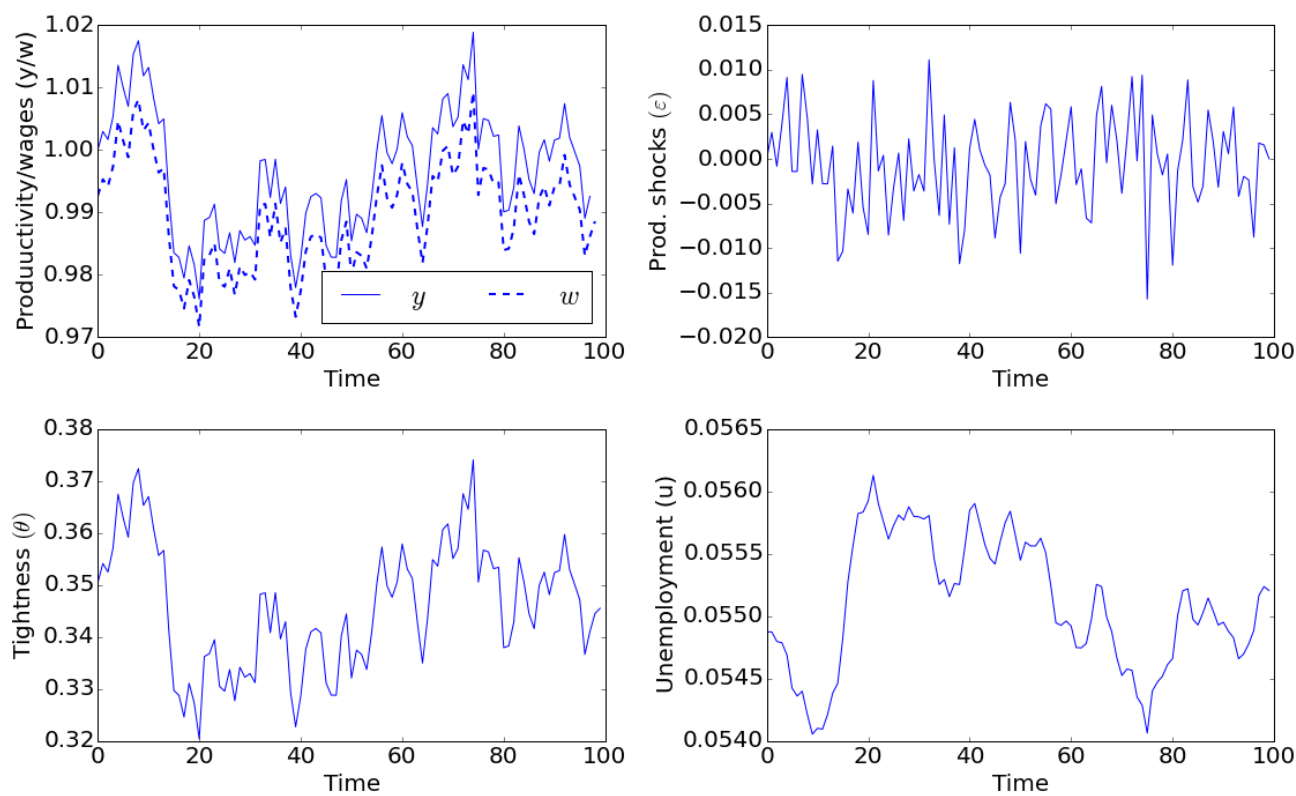

Figure C2: Convergence of agents' parameter estimates under decreasing gain learning to the REE values
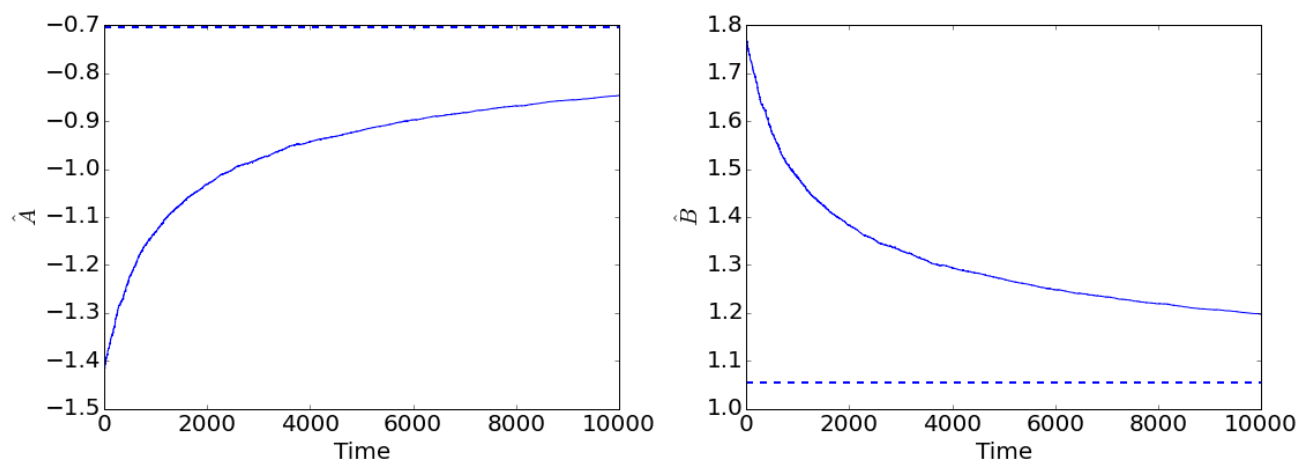

Note.- The simulation here is identical to that described under decreasing gain learning for Figure 2. Dashed lines give the true REE parameter values. 
Figure C3: Comparison of sample paths for endogenous variables under RE and decreasing gain learning, and agents' parameter estimates, following a structural shock
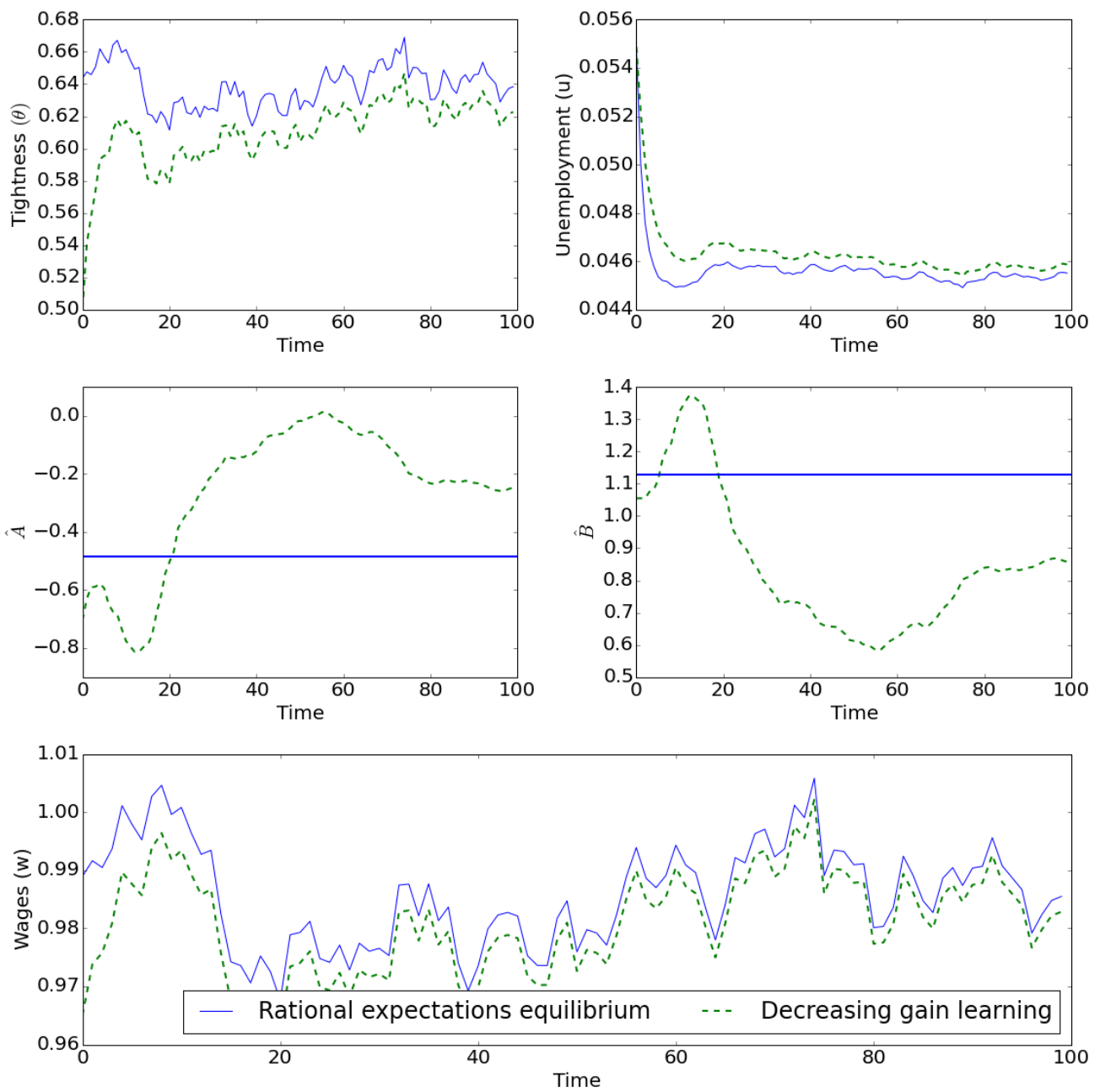

Note.- these simulation paths are the results of a negative $20 \%$ shock to the flow value of unemployment $b$, with initial parameter estimates assumed to be at the true pre-shock REE values. 
Figure C4: Comparing the speed of convergence to the REE under decreasing gain learning: changing worker bargaining power $\beta$
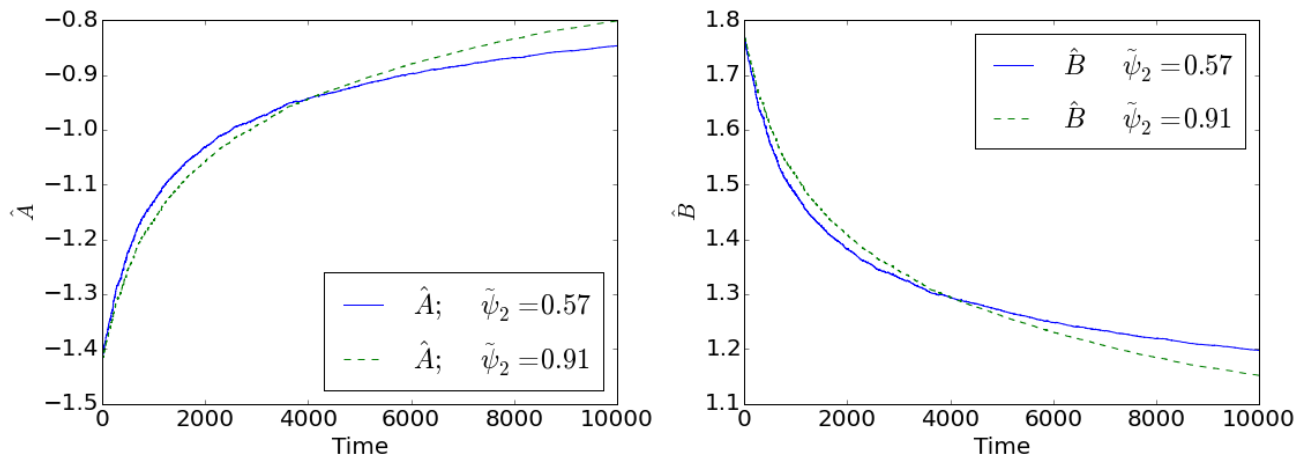

Note.- given $\beta=0.1$, then $\psi_{2}=0.91$. For $\beta=\alpha, \psi_{2}=0.57$, as in Figure 2 . The crossing of the time paths indicates a decreased speed of convergence since, for example, the REE parameter value with $\beta=0.1$ of $B=0.56$ is substantially lower than value with $\beta=\alpha$. 